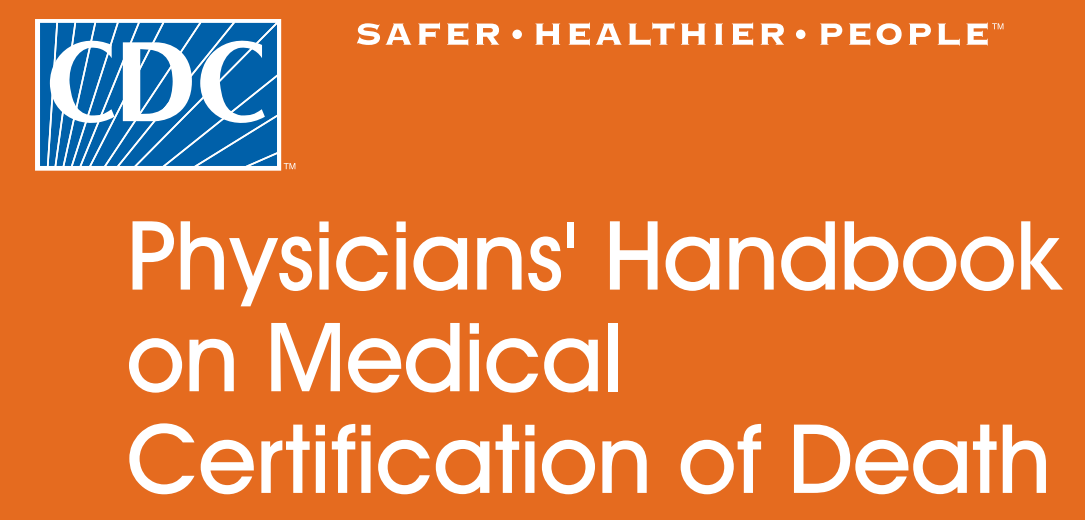

\title{
2003 Revision
}

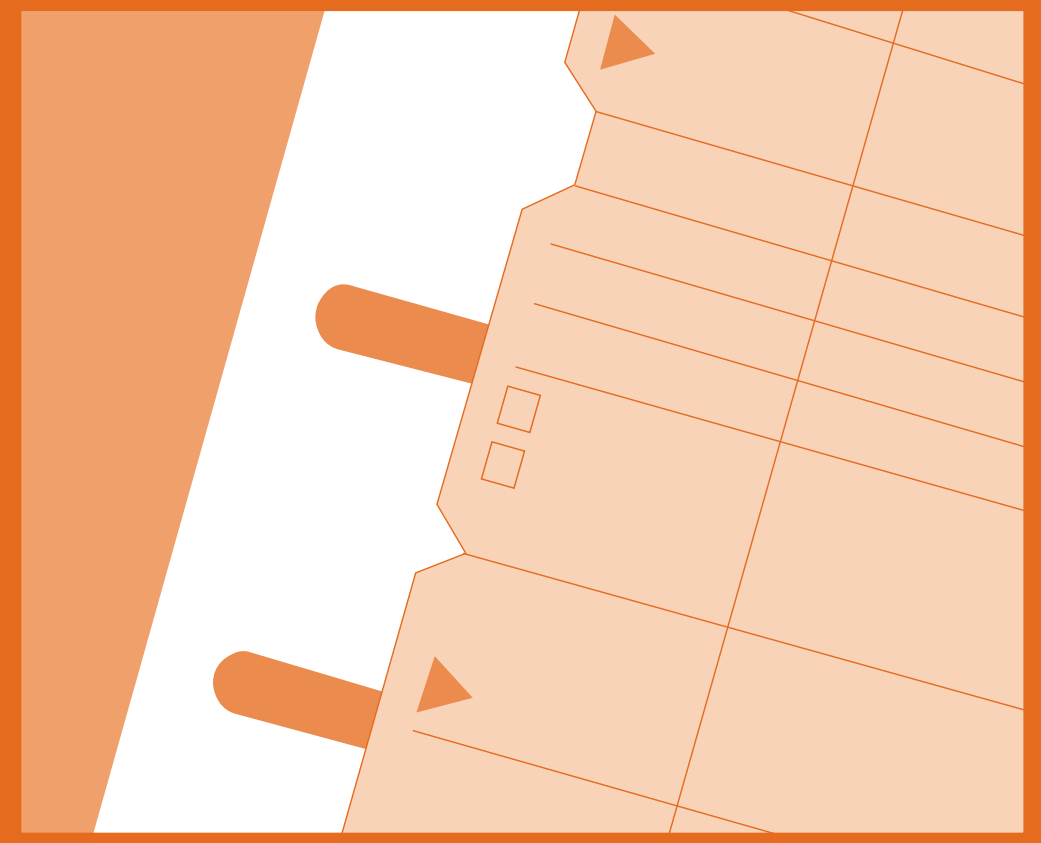

DEPARTMENT OF HEALTH AND HUMAN SERVICES

Centers for Disease Control and Prevention

National Center for Health Statistics 


\section{Physicians' Handbook on Medical Certification of Death}

\section{Revision}

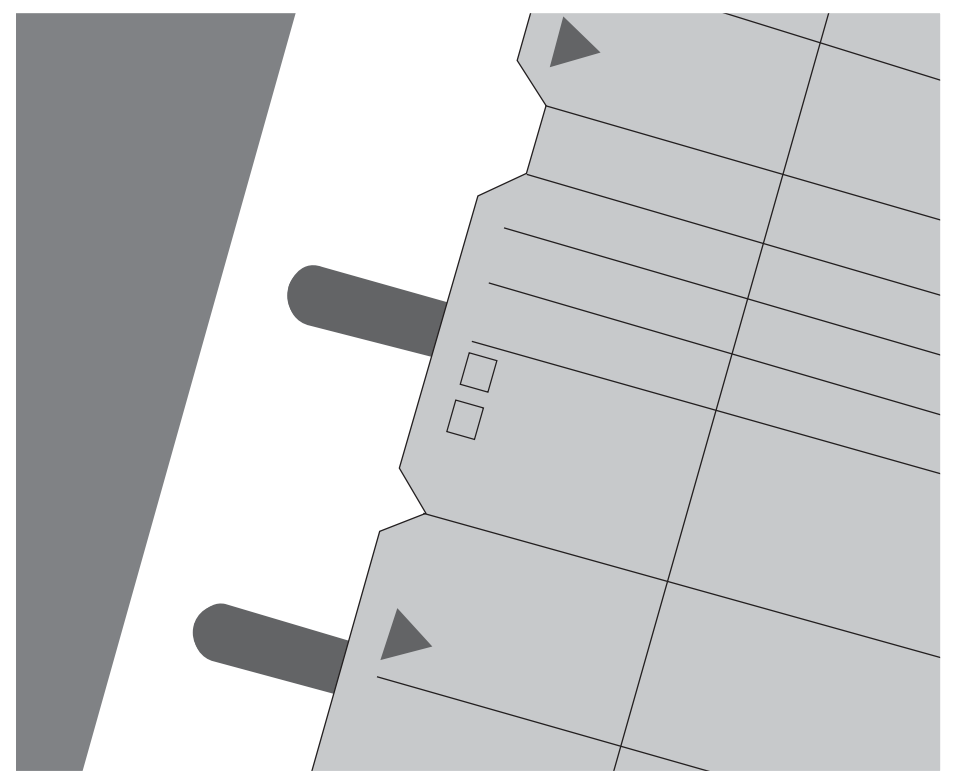

DEPARTMENT OF HEALTH AND HUMAN SERVICES

Centers for Disease Control and Prevention

National Center for Health Statistics

Hyattsville, Maryland

April 2003

DHHS Publication No. (PHS) 2003-1108 


\section{National Center for Health Statistics}

Edward J. Sondik, Ph.D., Director

Jack R. Anderson, Deputy Director

Jack R. Anderson, Acting Associate Director for

International Statistics

Jennifer H. Madans, Ph.D., Associate Director for Science

Lawrence H. Cox, Ph.D., Associate Director for Research

and Methodology

Diane M. Makuc, Dr.P.H., Acting Associate Director for

Analysis, Epidemiology, and Health Promotion

P. Douglas Williams, Acting Associate Director for Data

Standards, Program Development, and Extramural Programs

Edward L. Hunter, Associate Director for Planning, Budget, and Legislation

Jennifer H. Madans, Ph.D., Acting Associate Director for

Vital and Health Statistics Systems

Douglas L. Zinn, Acting Associate Director for

Management and Operations

Charles J. Rothwell, Associate Director for Information

Technology and Services

\section{Division of Vital Statistics}

James A. Weed, Ph.D., Acting Director

James A. Weed, Ph.D., Acting Chief, Mortality Statistics

Branch 


\section{Preface}

This handbook contains instructions for physicians on cause-of-death certification. It was prepared by the Department of Health and Human Services' Centers for Disease Control and Prevention's National Center for Health Statistics (NCHS). These instructions pertain to the 2003 revision of the U.S. Standard Certificate of Death and the 1992 revision of the Model State Vital Statistics Act and Regulations. This handbook serves as a model that can be adapted by any vital statistics registration area.

Other handbooks and references on preparing and registering vital records are mentioned at the end of the section on Medical Certification of Death and are listed in the references. For most of these resources, the State vital statistics office or NCHS can provide as many copies as desired.

For detailed information on completing other items on the death certificate, refer to the Medical Examiners' and Coroners' Handbook on Death Registration and Fetal Death Reporting or the Funeral Directors' Handbook on Death Registration and Fetal Death Reporting.

Keywords: medical certification $\bullet$ death certificate $\cdot$ guidelines $\bullet$ handbook 


\section{Acknowledgments}

This publication was prepared by staff from the Division of Vital Statistics led by Donna L. Hoyert, Ph.D., and Arialdi M. Minino, M.P.H. Robert N. Anderson, Ph.D., also contributed to this effort. Mary Anne Freedman, M.A., the Director of the Division of Vital Statistics while this publication was being prepared, reviewed and commented on the contents. Expert medical review and comments were provided by Randy Hanzlick, M.D.; Gregory G. Davis, M.D.; and Lillian R. Blackmon, M.D. Additional medical input was provided by Henry Thiede, M.D.; Kenneth C. Schoendorf, M.D.; and Sonja Rasmussen, M.D.

This handbook was edited by Demarius V. Miller, typeset by Jacqueline M. Davis, and the graphics produced by Jarmila G. Ogburn of the Publications Branch, Division of Data Services. 


\section{Contents}

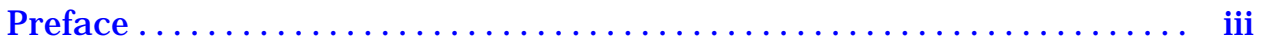

Acknowledgments .............................. v

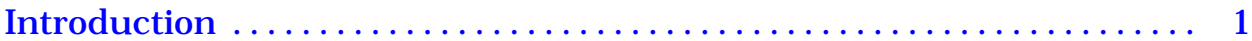

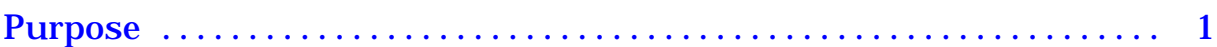

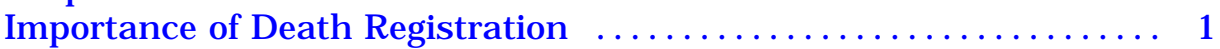

U.S. Standard Certificate of Death $\ldots . \ldots \ldots \ldots \ldots \ldots \ldots \ldots \ldots$

Confidentiality of Vital Records ...................... 4

Physician's Responsibility . ...................... 4

General Instructions for Completing Death Certificates $\ldots \ldots \ldots \ldots .7$

Medical Certification of Death ......................... 9

Pronouncing Date and Time of Death $\ldots \ldots \ldots \ldots \ldots \ldots \ldots$

Cause of Death .................................. 9

Changes to Cause of Death............................ 12

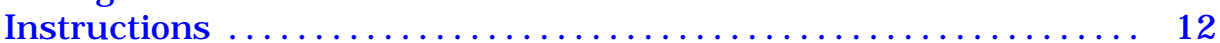

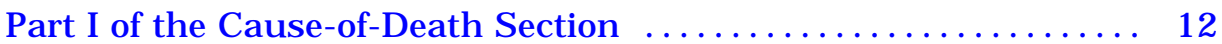

Line (a) Immediate Cause ......................... 13

Lines (b), (c), and (d) Due to (or as a Consequence of) ......... 13

Approximate Interval Between Onset and Death ............ 14

Part II of the Cause-of-Death Section (Other Significant

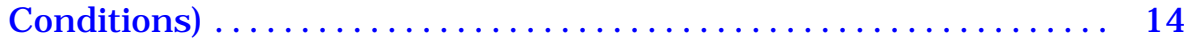

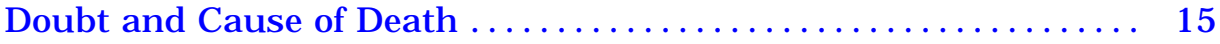

Other Items for Medical Certification $\ldots \ldots \ldots \ldots \ldots \ldots \ldots \ldots \ldots . . \ldots \ldots$

Completing the Certifier Section $\ldots \ldots \ldots \ldots \ldots \ldots \ldots \ldots \ldots \ldots \ldots$

Examples of Cause-of-Death Certification $\ldots \ldots \ldots \ldots \ldots \ldots \ldots \ldots$

Common Problems in Death Certification $\ldots \ldots \ldots \ldots \ldots \ldots . . . \ldots 31$

Additional Resources ................................. 33

Completing Other Items on the Death Certificate $\ldots \ldots \ldots \ldots \ldots .34$

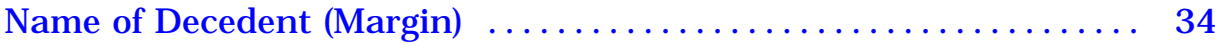

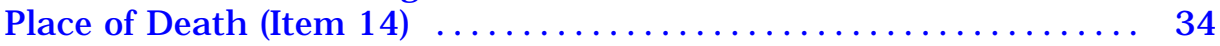

Facility Name (Items 15-17) $\ldots \ldots \ldots \ldots \ldots \ldots \ldots \ldots \ldots \ldots \ldots \ldots \ldots$

Date Pronounced Dead (Item 24) ...................... 36

Time Pronounced Dead (Item 25) $\ldots \ldots \ldots \ldots \ldots \ldots \ldots \ldots \ldots \ldots . \ldots \ldots$

Pronouncing Physician (Items 26-28) $\ldots \ldots \ldots \ldots \ldots \ldots \ldots \ldots \ldots \ldots$

Date Pronounced Dead (Item 29) .................... 38 
Time Pronounced Dead (Item 30) .................... 39

Was Medical Examiner or Coroner Contacted? (Item 31) ........ 40

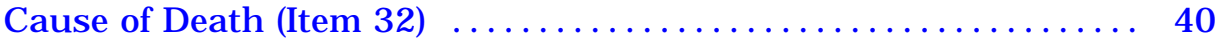

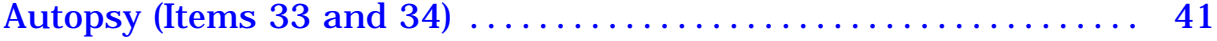

Tobacco Use Contribute to Death (Item 35) ................ 42

If Female, Pregnancy Status (Item 36) . . . . . . . . . . . . . . 42

Manner of Death (Item 37) ........................... 42

Accident or Injury (Items 38-44) ....................... 43

Certifier (Items 45-49)............................. 46

References.................................. 49

\section{Appendixes}

A. The U.S. Standard Certificate of Death ............... 52

B. The Vital Statistics Registration System in the United States ... 54 


\section{Introduction}

\section{Purpose}

This handbook is designed to acquaint physicians, medical students, and others with the vital registration system in the United States and to provide instructions for completing and filing death certificates. Emphasis is directed toward the certification of medical information, the primary responsibility of the physician, and a critical piece of information on the death certificate.

\section{Importance of death registration}

The death certificate is a permanent record of the fact of death, and depending on the State of death, may be needed to get a burial permit. State law specifies the required time for completing and filing the death certificate.

The death certificate provides important personal information about the decedent and about the circumstances and cause of death. This information has many uses related to the settlement of the estate and provides family members closure, peace of mind, and documentation of the cause of death.

The death certificate is the source for State and national mortality statistics (figures 1-3) and is used to determine which medical conditions receive research and development funding, to set public health goals, and to measure health status at local, State, national, and international levels. The Centers for Disease Control and Prevention's National Center for Health Statistics (NCHS) publishes summary mortality data in the $\mathrm{Na}^{-}$ tional Vital Statistics Report publication "Deaths: Final data" and on the Internet at http://www.cdc.gov/nchs (under vital statistics, mortality).

These mortality data are valuable to physicians indirectly by influencing funding that supports medical and health research that may alter clinical practice and directly as a research tool. Research topics include identifying disease etiology, evaluating diagnostic and therapeutic techniques, 


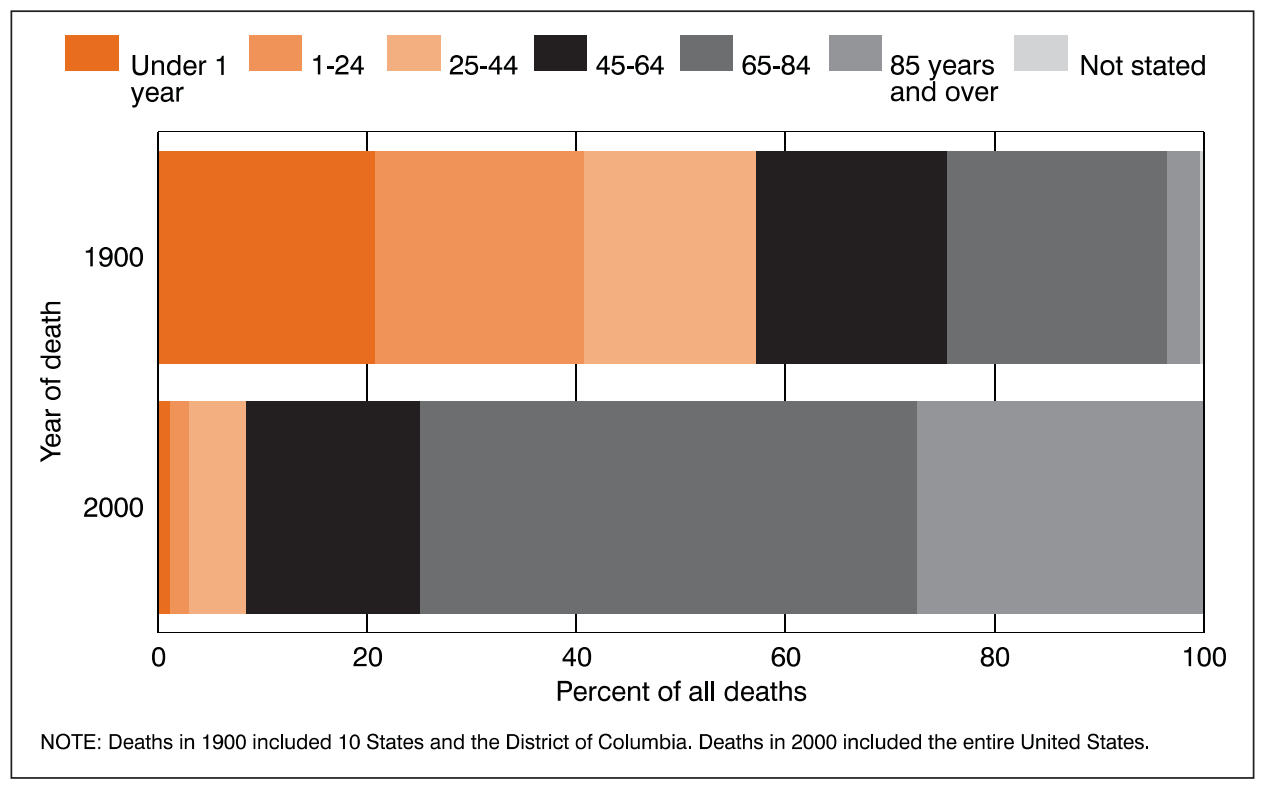

Figure 1. Deaths by age

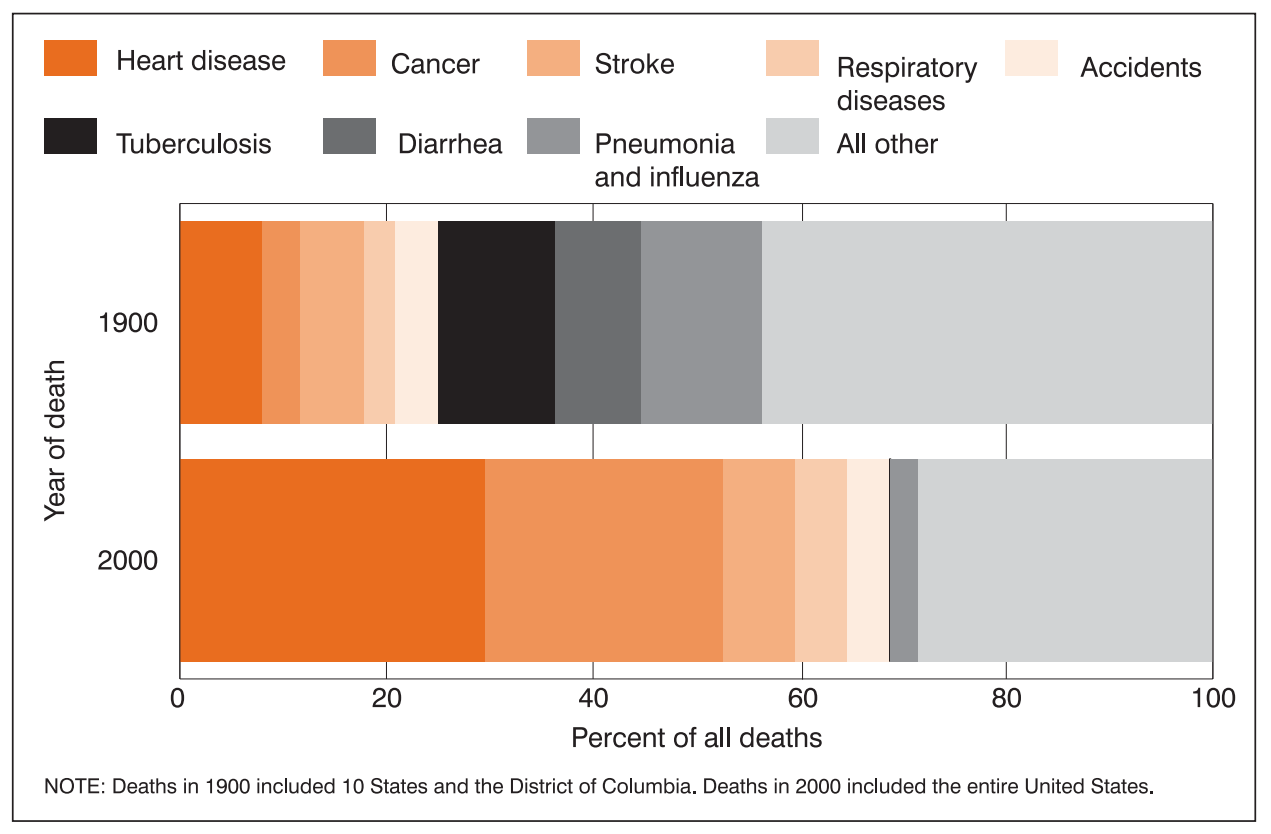

Figure 2. Deaths by cause 


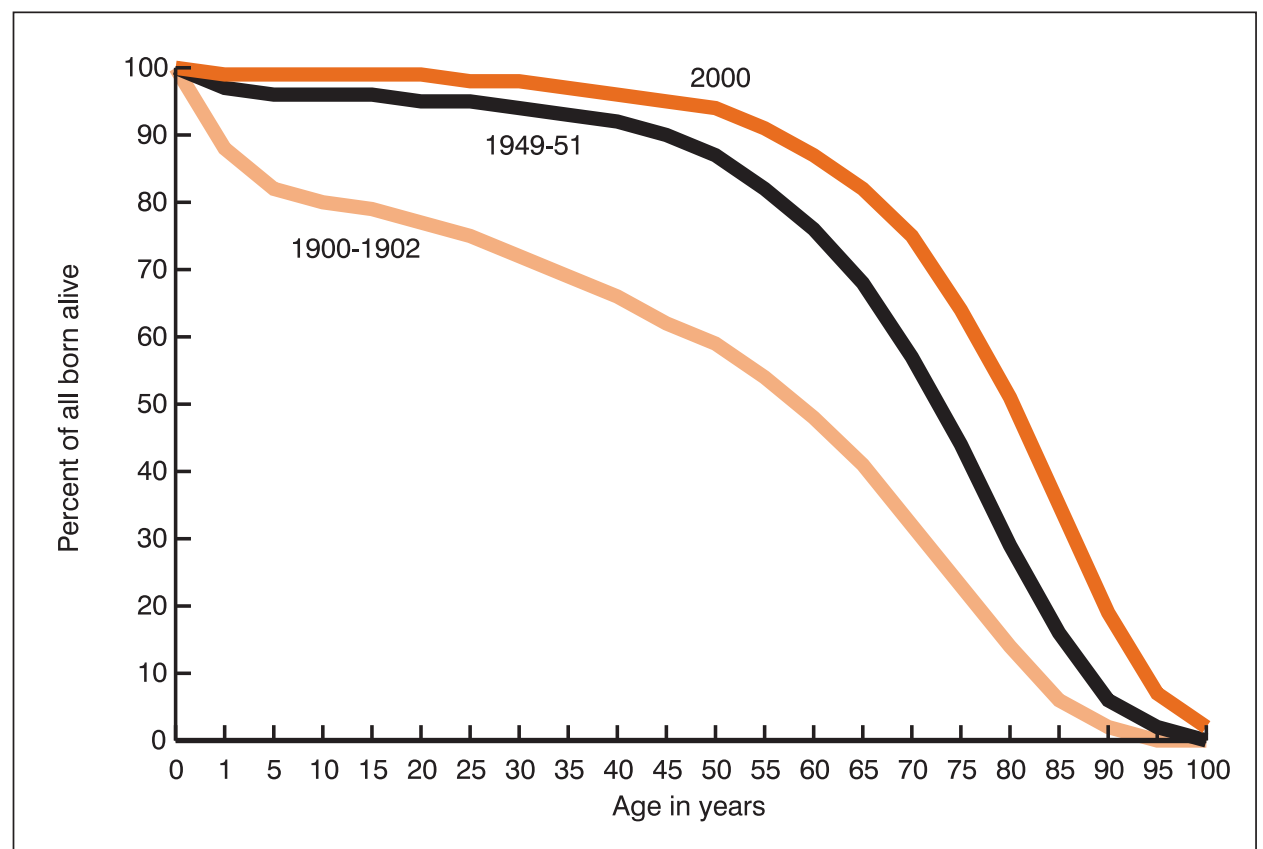

Figure 3. Percent of persons born alive in selected years surviving to specific ages

examining medical or mental health problems that may be found among specific groups of people (1), and indicating areas in which medical research can have the greatest impact on reducing mortality.

Analyses typically focus on a single condition reported on the death certificate, but some analyses do consider all conditions mentioned. Such analyses are important in studying certain diseases and conditions and in investigating relationships between conditions reported on the same death certificate (for example, types of fatal injuries and automobile crashes or types of infections and HIV).

Because statistical data derived from death certificates can be no more accurate than the information on the certificate, it is very important that all persons concerned with the registration of deaths strive not only for complete registration, but also for accuracy and promptness in reporting these events. Furthermore, the potential usefulness of detailed specific information is greater than more general information.

\section{U.S. Standard Certificate of Death}

The registration of deaths is a State function supported by individual State laws and regulations. The original death certificates are filed in the States 
and stored in accordance with State practice. Each State has a contract with NCHS that allows the Federal Government to use information from the State records to produce national vital statistics. The national data program is called the National Vital Statistics System (NVSS) $(2,3)$.

To ensure consistency in the NVSS, NCHS provides leadership and coordination in the development of a standard certificate of death for the States to use as a model. The standard certificate is revised periodically to ensure that the data collected relate to current and anticipated needs. In the revision process, stakeholders review and evaluate each item on the standard certificate for its registration, legal, genealogical, statistical, medical, and research value. The associations on the stakeholder panel that recommended the current U.S. Standard Certificate of Death included the American Medical Association, the National Association of Medical Examiners, the College of American Pathologists, and the American Hospital Association (2).

Most State certificates conform closely in content and arrangement to the standard. Minor modifications are sometimes necessary to comply with State laws or regulations or to meet specific information needs. Having similar forms promotes uniformity of data and comparable national statistics. They also allow the comparison of individual State data with national data and of individual State data with national data and data from other States. Uniformity of death certificates among the States also increases their acceptability as legal records.

\section{Confidentiality of vital records}

To encourage appropriate access to vital records, NCHS promotes the development of model vital statistics laws concerning confidentiality (4). State laws and supporting regulations define which persons have authorized access to vital records. Some States have few restrictions on access to death certificates. However, there are restrictions on access to death certificates in the majority of States. Legal safeguards to the confidentiality of vital records have been strengthened over time in some States.

\section{Physician's responsibility}

The physician's principal responsibility in death registration is to complete the medical part of the death certificate. In fulfilling the role of the certifier (i.e., person completing the medical part of the death certificate), the physician performs the final act of care to a patient by providing closure with a well-thought-out and complete death certificate that will allow the 
family to close the person's affairs. At the same time, the physician performs a service for the larger community.

The physician is to:

- Be familiar with State and local regulations on medical certifications for deaths without medical attendance or involving external causes that may require the physician to report the case to a medical examiner or coroner.

- Complete relevant portions of the death certificate.

- Deliver the signed or electronically authenticated death certificate to the funeral director promptly so that the funeral director can file it with the State or local registrar within the State's prescribed time period.

- Assist the State or local registrar by answering inquiries promptly.

- Deliver a supplemental report of cause of death to the State vital statistics office when autopsy findings or further investigation reveals the cause of death to be different from what was originally reported.

In some States, hospitals and other institutions are authorized to initiate the preparation of the death certificate when the death occurred in that hospital or institution. In such cases, the attending physician will usually complete the cause-of-death section and sign the certificate at the hospital or other institution. Jurisdictions with electronic registration systems may have other ways to authenticate the certification than by using a signature on paper. In a few States, when the attending physician (physician in charge of the patient's care for the condition that resulted in death) is not available at the time of death to certify the cause of death, another physician on duty at the hospital or other institution may pronounce the decedent legally dead; and, with the permission of the attending physician, the "pronouncing physician" may authorize release of the body to the funeral director. In such cases, the attending physician will certify the cause of death at a later time.

In all cases, the attending physician is responsible for certifying the cause of death. In most cases, he or she will both pronounce death and certify the cause of death. Only in the instances when the attending physician is unavailable to certify the cause of death at the time of death, and State law provides for a pronouncing physician, will a different physician pronounce death.

If completed properly, the cause of death will communicate the same essential information (11) that a case history would. For example, the following cause-of-death statement is complete: 
I a) Septic shock

b) Infected decubitus ulcers

c) Complications of cerebral infarction

d) Cerebral artery atherosclerosis

II Insulin-dependent diabetes mellitus

If not completed properly, information may be missing from the cause-ofdeath section, so someone reading the cause of death would not know why the condition on the lowest used line developed. For example:

\section{I a) Pneumonia}

b) Malnutrition

c)

II

This example does not explain what caused malnutrition. A variety of different circumstances could cause malnutrition, so the statement is incomplete and ambiguous.

In some cases, the physician will be contacted to verify information reported on a death certificate or to provide additional information to clarify what was meant. The original cause-of-death statement may not be wrong from a clinical standpoint, but may not include sufficient information for assigning codes for statistical purposes. Following guidelines in this handbook should minimize the frequency with which a physician will need to spend additional time answering follow-up questions about a patient's cause of death. 


\section{General Instructions for Completing Death Certificates}

Death certificates are permanent legal records from which official copies are made. It is essential that the certificate be prepared accurately. Funeral directors are responsible for completing most of the information on the death certificate with the assistance of an informant who is usually a family member.

Completing a death certificate involves the following guidelines:

- Use the current form designated by the State.

- Complete each item, following the specific instructions for that item.

- Make the entry legible. Use a computer printer with high resolution, typewriter with good black ribbon and clean keys, or print legibly using permanent black ink.

- Do not use abbreviations except those recommended in the specific item instructions.

- Verify with the informant the spelling of names, especially those that have different spellings for the same sound (Smith or Smyth, Gail or Gayle, Wolf or Wolfe, and so forth).

- Refer problems not covered in these instructions to the State office of vital statistics or to the local registrar.

- Obtain all signatures; rubber stamps or other facsimile signatures are not acceptable. If jurisdiction provides, authenticate electronically.

- Do not make alterations or erasures.

- File the original certificate or report with the registrar. Reproductions or duplicates are not acceptable.

Most States require that the death certificate be completed and filed within a specified time period. Physicians are expected to use medical training, knowledge of medicine, available medical history, symptoms, diagnostic tests, and autopsy results, if available, to determine the cause of death. Generally, it is possible to file a certificate with the cause of death listed as pending or pending further study. This is especially useful when additional 
investigation such as autopsy results are expected, but it obligates the attending physician to update the original information after the additional information becomes available. 


\section{Medical Certification of Death}

The physician's primary responsibility in death registration is pronouncing the death and, when he or she is the attending physician, reporting cause of death. The medical part of the certificate includes:

- Date and time pronounced dead

- Date and time of death

- Guestion on whether the case was referred to the medical examiner or coroner

- Cause-of-death section including cause of death, manner of death, tobacco use, and females' pregnancy status items

- Injury items for cases involving injuries

- Certifier section with signatures

In most cases, a physician will both pronounce death and certify or report the cause of death. A different physician will pronounce death only when the attending physician is unavailable to certify the cause of death at the time of death and if State law provides for this option. If an inquiry is required by a State Post-Mortem Examinations Act, a medical examiner or coroner is responsible for determining cause of death (4).

\section{Pronouncing date and time of death}

Items 24 and 25 must be completed by the person who pronounces death. This may be the pronouncing physician, pronouncing/certifying physician, or the medical examiner or coroner. For cases involving a pronouncing physician different from the certifying physician, the pronouncing physician must also complete items 26-28.

\section{Cause of death}

This section must be completed by either the attending physician, the medical examiner, or the coroner. The cause-of-death section, a facsimile of which is shown below, follows guidelines recommended by the World Health Organization. An important feature is the reported underlying cause 
of death determined by the certifying physician and defined as (a) the disease or injury that initiated the train of morbid events leading directly to death, or (b) the circumstances of the accident or violence that produced the fatal injury. In addition to the underlying cause of death, this section provides for reporting the entire sequence of events leading to death as well as other conditions significantly contributing to death (5).

The cause-of-death section is designed to elicit the opinion of the medical certifier. Causes of death on the death certificate represent a medical opinion that might vary among individual physicians. A properly completed cause-of-death section provides an etiologic explanation of the order, type, and association of events resulting in death. The initial condition that starts the etiologic sequence is specific if it does not leave any doubt as to why it developed. For example, sepsis is not specific because a number of different conditions may have resulted in sepsis, whereas human immunodeficiency virus syndrome is specific.

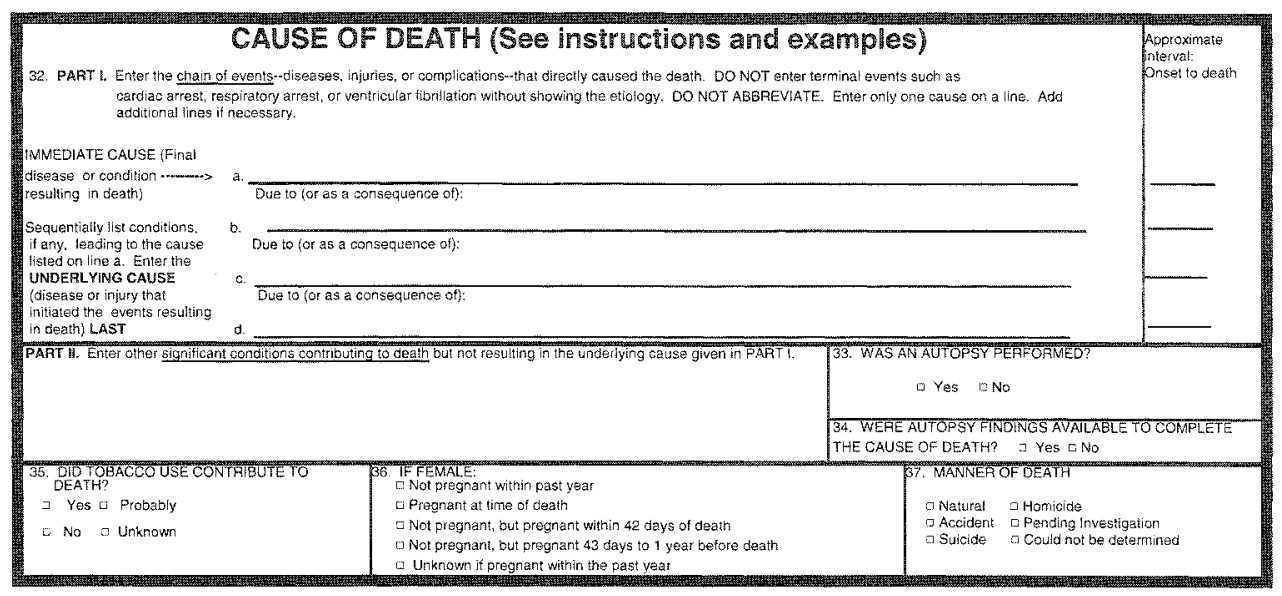

In certifying the cause of death, any disease, abnormality, injury, or poisoning, if believed to have adversely affected the decedent, should be reported. If the use of alcohol and/or other substance, a smoking history, a recent pregnancy, injury, or surgery was believed to have contributed to death, then this condition should be reported. The conditions present at the time of death may be completely unrelated, arising independently of each other; they may be causally related to each other, that is, one condition may lead to another which in turn leads to a third condition; and so forth. Death may also result from the combined effect of two or more conditions. 
As can be seen, the cause-of-death section consists of two parts. The first part is for reporting the sequence of events leading to death, proceeding backwards from the final disease or condition resulting in death. So each condition in Part I should cause the condition above it. A specific cause of death should be reported in the last entry in Part I so there is no ambiguity about the etiology of this cause. Other significant conditions that contributed to the death, but did not lead to the underlying cause, are reported in Part II.

In addition, there are questions relating to autopsy, manner of death (for example, accident), and injury. The cause of death should include information provided by the pathologist if an autopsy or other type of postmortem examination is done. For deaths that have microscopic examinations pending at the time the certificate is filed, the additional information should be reported as soon as it is available. If the physician has any questions about the procedure for doing this, he or she should contact his or her State registrar.

For statistical and research purposes, it is important that the causes of death and, in particular, the underlying cause of death be reported as specifically and as precisely as possible. Careful reporting results in statistics for both underlying and multiple causes of death (i.e., all conditions mentioned on a death certificate) reflecting the best medical opinion.

Every cause-of-death statement is coded and tabulated in the statistical offices according to the latest revision of the International Classification of Diseases (5). When there is a problem with the reported cause of death (e.g., when a causal sequence is reported in reverse order), the rules provide a consistent way to select the most likely underlying cause. However, it is better when rules designed to compensate for poor reporting are not invoked so that the rules are confirming the physician's statement rather than imposing assumptions about what the physician meant.

Statistically, mortality research focuses on the underlying cause of death because public health interventions seek to break the sequence of causally related medical conditions as early as possible. However, all cause information reported on death certificates is important and is analyzed.

In the sections that follow, detailed instructions on how to complete Parts I and II are given. A number of examples of properly completed certificates with case histories are provided in this section to illustrate how the cause of death should be reported. Some common problems are also discussed later in this section. 


\section{Changes to cause of death}

Should additional medical information or autopsy findings become available that would change the cause or causes of death originally reported, the certifying physician should amend the original death certificate by immediately reporting the revised cause of death to the State vital records office or local registrar.

\section{Instructions}

The cause-of-death section consists of two parts. Part I is for reporting a chain of events leading directly to death, with the immediate cause of death (the final disease, injury, or complication directly causing death) on line (a) and the underlying cause of death (the disease or injury that initiated the chain of events that led directly and inevitably to death) on the lowest used line. Part II is for reporting all other significant diseases, conditions, or injuries that contributed to death but which did not result in the underlying cause of death given in Part I.

The cause-of-death information should be the physician's best medical OPINION. Report each disease, abnormality, injury, or poisoning that the physician believes adversely affected the decedent. A condition can be listed as "probable" if it has not been definitively diagnosed.

If an organ system failure such as congestive heart failure, hepatic failure, renal failure, or respiratory failure is listed as a cause of death, always report its etiology on the line(s) beneath it (for example, renal failure due to Type I diabetes mellitus).

When indicating neoplasms as a cause of death, include the following: 1) primary site or that the primary site is unknown, 2) benign or malignant, 3) cell type or that the cell type is unknown, 4) grade of neoplasm, and 5) part or lobe of organ affected. (For example, a primary well-differentiated squamous cell carcinoma, lung, left upper lobe.)

For each fatal injury (for example, stab wound of chest), always report the trauma (for example, transection of subclavian vein), and impairment of function (for example, air embolism) that contributed to death.

\section{Part I of the cause-of-death section}

Only one cause is to be entered on each line of Part I. Additional lines should be added between the printed lines when necessary. For each cause, indicate in the space provided the approximate interval between the date of onset (not necessarily the date of diagnosis) and the date of death. 
For clarity, do not use parenthetical statements and abbreviations when reporting the cause of death. The underlying cause of death should be entered on the LOWEST LINE USED IN PART I. The underlying cause of death is the disease or injury that started the sequence of events leading directly to death or the circumstances of the accident or violence that produced the fatal injury. In the case of a violent death, the form of external violence or accident is antecedent to an injury entered, although the two events may be almost simultaneous.

\section{Line (a) immediate cause}

In Part I, the immediate cause of death is reported on line (a). This is the final disease, injury, or complication directly causing the death. An immediate cause of death must always be reported on line (a). It can be the sole entry in the cause-of-death section if that condition is the only condition causing the death.

The immediate cause does not mean the mechanism of death or terminal event (for example, cardiac arrest or respiratory arrest). The mechanism of death (for example, cardiac or respiratory arrest) should not be reported as the immediate cause of death as it is a statement not specifically related to the disease process, and it merely attests to the fact of death. Therefore, the mechanism of death provides no additional information on the cause of death.

\section{Lines (b), (c), and (d) due to (or as a consequence of)}

On line (b) report the disease, injury, or complication, if any, that gave rise to the immediate cause of death reported on line (a). If this in turn resulted from a further condition, record that condition on line (c). If this in turn resulted from a further condition, record that condition on line (d). For as many conditions as are involved, write the full sequence, one condition per line, with the most recent condition at the top, and the underlying cause of death reported on the lowest line used in Part I. If more than four lines are needed, add additional lines (writing "due to" between conditions on the same line is the same as drawing an additional line) rather than using space in Part II to continue the sequence. The following certification is an example in which an additional line was necessary. 


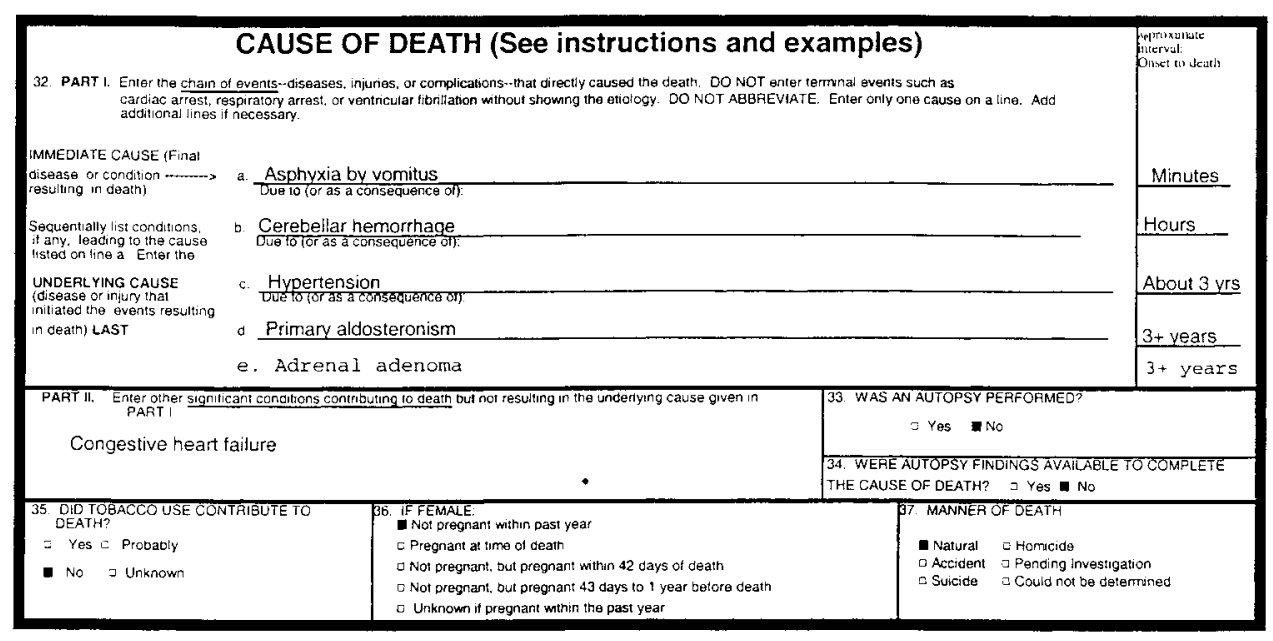

The words "due to (or as a consequence of)," which are printed between the lines of Part I, apply not only in sequences with an etiological or pathological basis and usually a chronological time ordering, but also to sequences in which an antecedent condition is believed to have prepared the way for a subsequent cause by damage to tissues or impairment of function.

If the immediate cause of death arose as a complication of or from an error or accident in surgery or other medical procedure or treatment, it is important to report what condition was being treated, what medical procedure was performed, what the complication or error was, and what the result of the complication or error was.

\section{Approximate interval between onset and death}

Space is provided to the right of lines (a), (b), (c), and (d) for recording the interval between the presumed onset of the condition (not the diagnosis of the condition) and the date of death. This should be entered for all conditions in Part I. These intervals usually are established by the physician on the basis of available information. In some cases the interval will have to be estimated. The terms "unknown" or "approximately" may be used. General terms, such as minutes, hours, or days, are acceptable, if necessary. If the time of onset is entirely unknown, state that the interval is "Unknown." Do not leave these items blank.

This information is useful in coding certain diseases and also provides a useful check on the accuracy of the reported sequence of conditions.

\section{Part II of the cause-of-death section (other significant conditions)}

All other important diseases or conditions that were present at the time of death and that may have contributed to the death, but did not lead to the 
underlying cause of death listed in Part I or were not reported in the chain of events in Part I, should be recorded on these lines. (More than one condition can be reported per line in Part II.)

Multiple conditions and sequences of conditions resulting in death are common, particularly among the elderly. When there are two or more possible sequences resulting in death, or if two conditions seem to have added together, choose and report in Part I the sequence thought to have had the greatest impact. Other conditions or conditions from the other sequence(s) should be reported in Part II. For example, in the case of a diabetic male with chronic ischemic heart disease who dies from pneumonia, his certifying physician must choose the sequence of conditions that had the greatest impact and report this sequence in Part I. One possible sequence that the certifier might report would be pneumonia due to diabetes mellitus in Part I with chronic ischemic heart disease reported in Part II. Another possibility would be pneumonia due to the chronic ischemic heart disease entered in Part I with diabetes mellitus reported in Part II. Or the certifier might consider the pneumonia to be due to the ischemic heart disease that was due to the diabetes mellitus and report this entire sequence in Part I. Because these three different possibilities would be coded very differently, it is important for the certifying physician to decide which sequence most accurately describes the conditions causing death.

\section{Doubt and cause of death}

In cases of doubt, it may be necessary to use qualifying phrases in either Part I or Part II to reflect uncertainty as to which conditions led to death. In cases where the certifier is unable to establish a cause of death based upon reasonable medical certainty, he or she should enter "Unknown" in the cause-of-death section. However, this should be shown only after all efforts have been made to determine the cause of death. An autopsy should be performed, if possible.

\section{Other items for medical certification}

The remaining items that require the physician's certification relate to autopsy, manner of death, injury, female decedent's pregnancy status, if tobacco use contributed to death, and whether the case was referred to the medical examiner or coroner.

The physician should indicate whether an autopsy was performed and whether the findings were available to complete the cause of death. If additional medical information or autopsy findings are received after the 
physician has certified the cause of death and he or she determines the cause to be different from what was originally entered on the death certificate, the original certificate should be amended by filing a supplemental report of cause of death with the State registrar. Information on the proper form to use and procedure to follow can be obtained from the State registrar.

In most cases the manner of death will be checked "Natural." In those cases when an accident, suicide, or homicide has occurred, the medical examiner or coroner must be notified. If the medical examiner or coroner does not assume jurisdiction, the physician should check the appropriate manner of death and describe the injury and accident.

\section{Completing the certifier section}

Physicians can play different roles in medical certification. A pronouncing physician is a physician who determines that the decedent is legally dead, but was not in charge of the patient's care for the illness or condition that resulted in death. The attending physician is responsible for completing the cause-of-death section (item 32). If a pronouncing physician is involved, the attending physician plays the role of a certifying physician. If no pronouncing physician is involved, the attending physician plays the role of both the pronouncing and certifying physician. The medical examiner or coroner investigates certain types of deaths according to State law and complete the cause of death for these cases.

The following chart specifies the items to be completed by each type of medical certifier.

\section{MEDICAL CERTIFICATION}

Medical certifier

Pronouncing physician

Certifying physician

Pronouncing and certifying physician

Medical examiner or coroner
Complete items

$24-31$

32-37, 45-49 (sometimes 38-44)

$24,25,29-37$, and 45-49

(sometimes 38-44)

$24,25,29,30$, and $32-49$

The attending physician is usually in a better position than any other individual to make a judgment as to which of the conditions led directly to death and to state the antecedent conditions, if any, that gave rise to this cause. 
Because the items completed by the pronouncing or pronouncing and certifying physician, and medical examiner or coroner differ, separate statements are provided that specify to what information each physician is attesting. This agreement is denoted when each physician signs the completed statement, adding his or her degree or title and license number. Certain jurisdictions may provide for electronic authentication instead of a signature on the paper document. The date of certification and mailing address of the physician should also be provided.

\section{Examples of cause-of-death certification}

\section{Case history no. 1}

Shortly after dinner on the day prior to admission to the hospital, this 48-year-old male developed a cramping, epigastric pain, which radiated to his back, followed by nausea and vomiting. The pain was not relieved by positional changes or antacids. The pain persisted, and 24 hours after its onset, the patient sought medical attention. He had a 10-year history of excessive alcohol consumption and a 2-year history of frequent episodes of similar epigastric pain. The patient denied diarrhea, constipation, hematemesis, or melena. The patient was admitted to the hospital with a diagnosis of an acute exacerbation of chronic pancreatitis. Radiological findings included a duodenal ileus and pancreatic calcification. Serum amylase was 4,032 units per liter. The day after admission, the patient seemed to improve. However, that evening he became disoriented, restless, and hypotensive. Despite intravenous fluids and vasopressors, the patient remained hypotensive and died. Autopsy findings revealed many areas of fibrosis in the pancreas with the remaining areas showing multiple foci of acute inflammation and necrosis. 


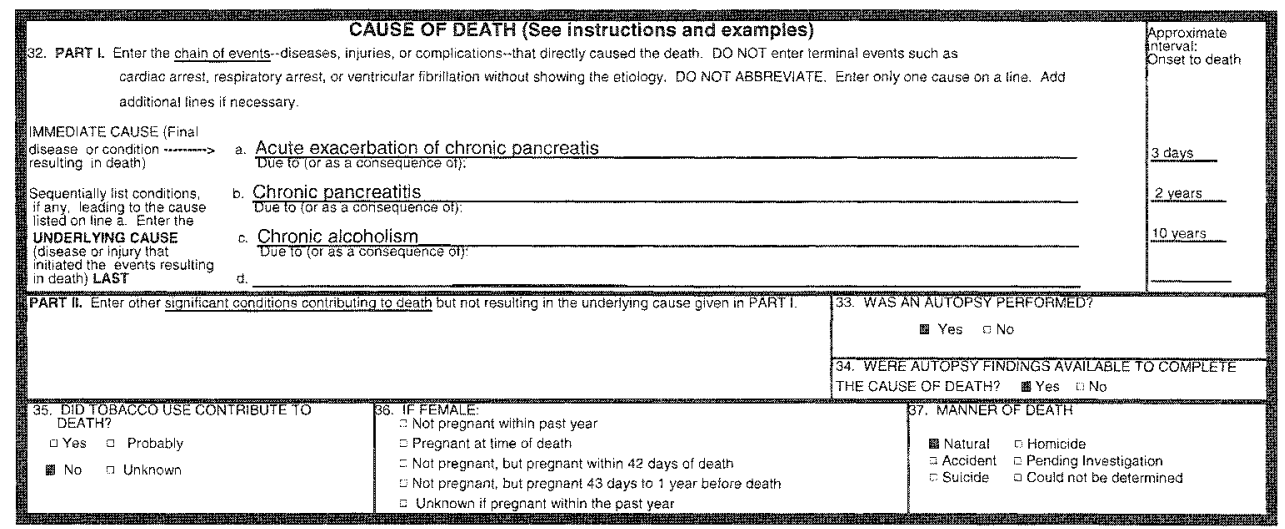

Notes on death certification:

Duodenal ileus and pancreatic calcification are nonspecific processes and neither could be listed as an underlying cause of death.

\section{Case history no. 2}

A 68-year-old male was admitted to the hospital with progressive right lower quadrant pain of several weeks' duration. The patient had lost approximately 40 pounds, with progressive weakness and malaise. On physical examination, the patient had an enlarged liver span that was four finger breadths below the right costal margin. Rectal examination was normal and stool was negative for occult blood. Routine laboratory studies were within normal limits. A chest $\mathrm{x}$ ray and barium enema were negative. His EKG showed a right bundle branch block. CT scan showed numerous masses within both lobes of the liver. A needle biopsy of the liver was diagnostic of moderately differentiated hepatocellular carcinoma, and the patient was started on chemotherapy. Three months after the diagnosis, the patient developed sharp diminution of liver function as well as a deep venous thrombosis of his left thigh, and he was admitted to the hospital. On his third day, the patient developed a pulmonary embolism and died 30 minutes later. 


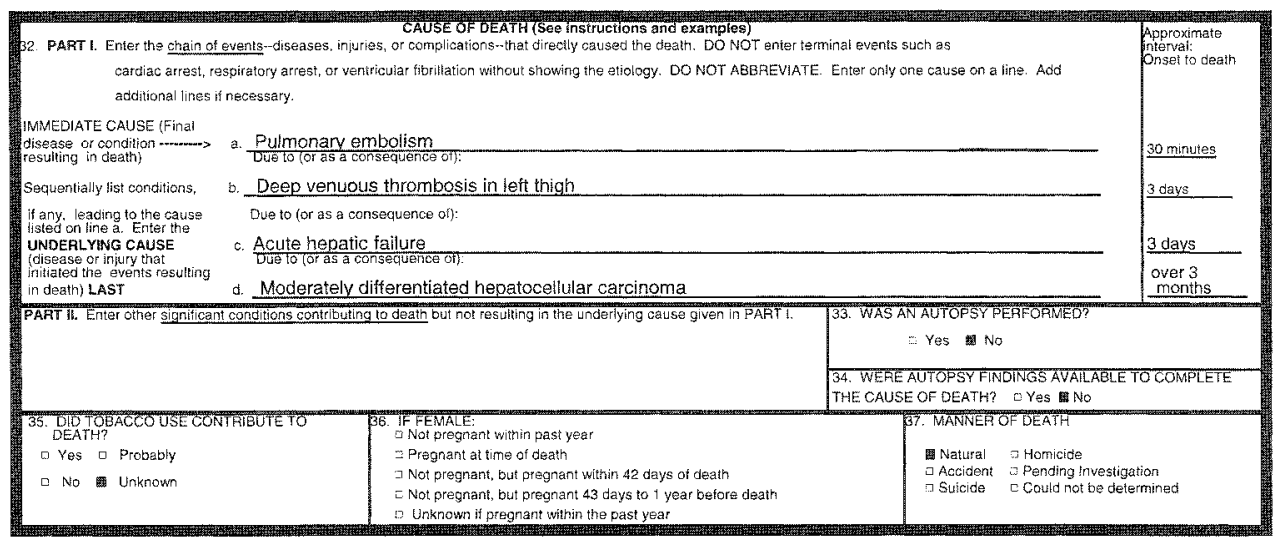

\section{Case history no. 3}

This 75-year-old male was admitted to the hospital complaining of severe chest pain. He had a 10-year history of arteriosclerotic heart disease with EKG findings of myocardial ischemia and several episodes of congestive heart failure controlled by digitalis preparations and diuretics. Five months before this admission, the patient was found to be anemic, with an hematocrit of 17, and to have occult blood in the stool. A barium enema revealed a large polypoid mass in the cecum diagnosed as carcinoma by biopsy.

Because of the patient's cardiac status, he was not considered to be a surgical candidate. Instead, he was treated with a 5-week course of radiation therapy and periodic packed red cell transfusions. He completed this course 3 months before this hospital admission. On this admission the EKG was diagnostic of an acute anterior wall myocardial infarction. He expired 2 days later. 


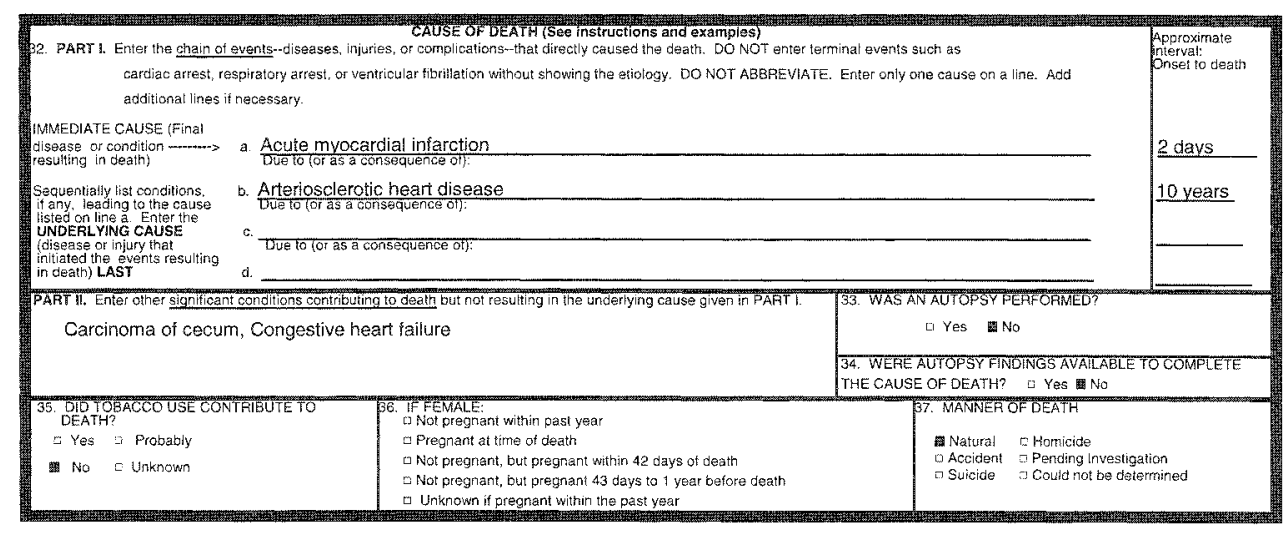

Notes on death certification:

Acute myocardial infarction, listed in Part I line (a) as the immediate cause of death, is a direct consequence of arteriosclerotic heart disease, the underlying cause listed in Part I line (b).

Carcinoma of cecum is listed in Part II because it caused anemia and weakened the patient, but it did not cause arteriosclerotic heart disease.

Congestive heart failure is listed in Part II because it also weakened the patient. Although it was caused by the arteriosclerotic heart disease, it was not part of the causal sequence leading to the acute myocardial infarction.

\section{Case history no. 4}

A 68-year-old female was admitted to the ICU with dyspnea and moderate retrosternal pain of 5-hours duration, which did not respond to nitroglycerin. There was a past history of obesity, noninsulin-dependent diabetes mellitus, hypertension, and episodes of nonexertional chest pain, diagnosed as angina pectoris, for 8 years. Over the first 72 hours, she developed a significant elevation of the MB isoenzyme of creatine phosphokinase, confirming an acute myocardial infarction. A Type II second-degree AV block developed, and a temporary pacemaker was put in place. She subsequently developed dyspnea with fluid retention and cardiomegaly on chest radiograph. She improved with diuretics. On the seventh hospital day, during ambulation, she suddenly developed chest pain and increased dyspnea. An acute pulmonary embolism was suspected and intravenous heparin was started. The diagnosis of pulmonary embolism was confirmed by a ventilation/perfusion scan as well as arterial blood gas measurements. One hour later, she became unresponsive and resuscitation efforts were unsuccessful. 


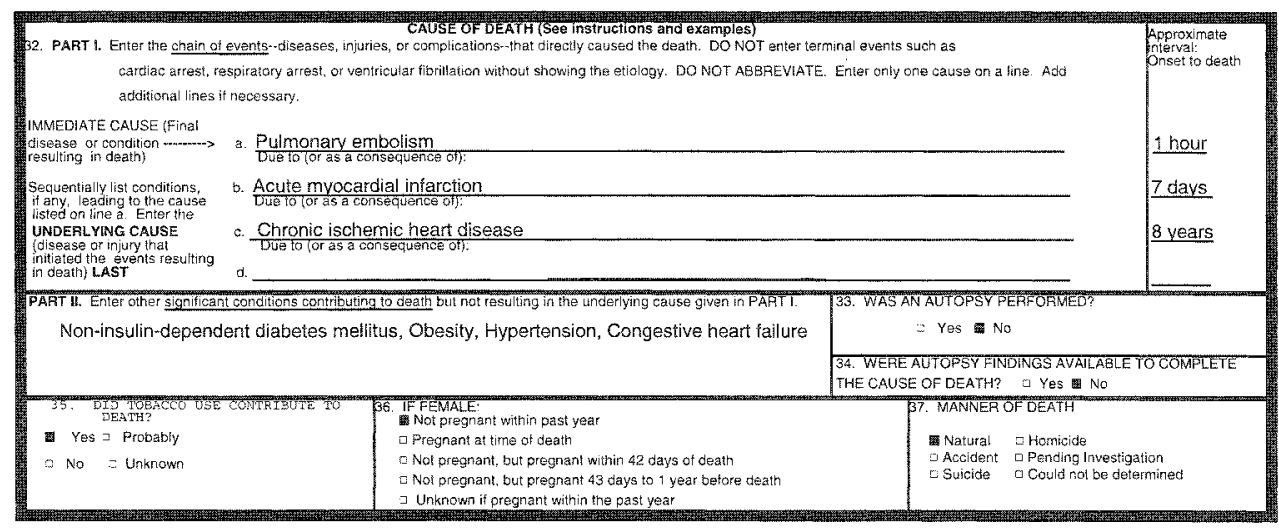

Notes on death certification:

In this case, noninsulin-dependent diabetes mellitus, obesity, hypertension, and congestive heart failure would all be considered factors that contributed to the death. However, they would not be in the direct causal sequence of Part I, so they would be placed in Part II.

\section{Case history no. 5}

A 78-year-old female with a temperature of $102.6^{\circ} \mathrm{F}$ was admitted to the hospital from a nursing home. She first became a resident of the nursing home 2 years earlier following a cerebrovascular accident, which left her with a residual left hemiparesis. Over the next year, she became increasingly dependent on others to help with her activities of daily living, eventually requiring an in-dwelling bladder catheter 6 months before the current admission. For the 3 days prior to admission, she was noted to have lost her appetite and to have become increasingly withdrawn.

On admission to the hospital her leukocyte count was 19,700, she had pyuria, and gram-negative rods were seen on a gram stain of urine. Ampicillin and gentamicin were administered intravenously. On the third hospital day, admission blood cultures turned positive for Pseudomonas aeruginosa, which was resistant to ampicillin and gentamicin. Antibiotic therapy was changed to ticarcillin clavulanate, to which the organism was sensitive. Despite the antibiotics and intravenous fluid support, the patient's fever persisted. On the fourth hospital day, she became hypotensive and died.

This case illustrates that additional lines may be added to Part I. 


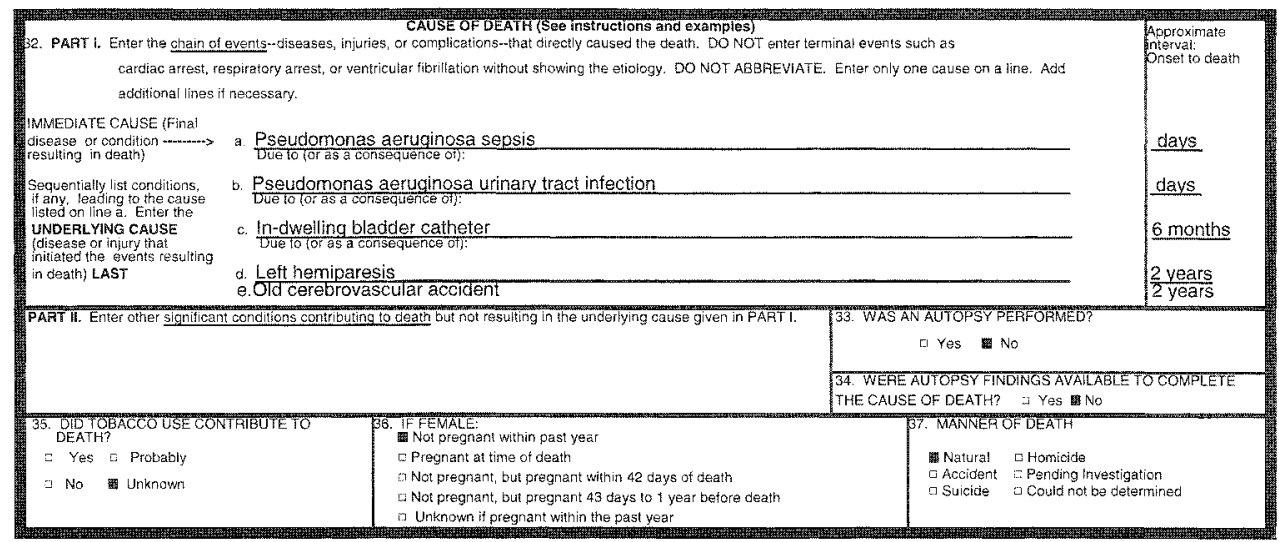

\section{Case history no. 6}

A 34-year-old male was admitted to the hospital with severe shortness of breath. He had a 9-month history of unintentional weight loss, night sweats, and diarrhea. The patient had no history of any medical condition that would cause immunodeficiency. An Elisa test and confirmatory Western Blot test for human immunodeficiency virus (HIV) were positive. $\mathrm{T}$-lymphocyte tests indicated a low $\mathrm{T}$ helper-suppressor ratio. A lung biopsy was positive for pneumocystis carinii pneumonia (PCP), indicating a diagnosis of acquired immunodeficiency syndrome (AIDS).

The patient's pneumonia responded to pentamidine therapy, and the patient was discharged. The patient had two additional admissions for PCP. Seventeen months after the patient was first discovered to be HIV positive, he again developed PCP but did not respond to therapy. He died 2 weeks later. 


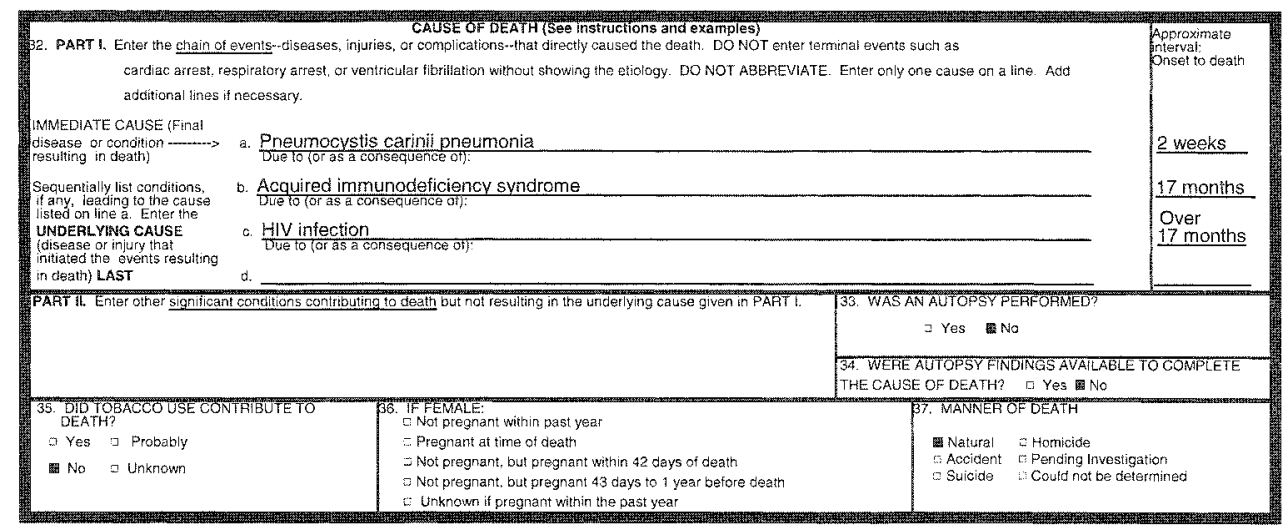

Notes on death certification:

By definition, AIDS is due to HIV infection; even though it may seem redundant to specify HIV infection in the causal sequence death, it is desirable to do so. HIV infection and AIDS are not synonymous, and there is a variable clinical course between the time of HIV infection and onset of AIDS.

\section{Case history no. 7}

A 75-year-old male had a 10-year history of chronic bronchitis associated with smoking two packs of cigarettes a day for more than 40 years. When seen by his physician approximately 2 years prior to his terminal episode, he had moderately reduced $\mathrm{FEV}_{1}$ and $\mathrm{FVC}$ with no response to bronchodilators. During his last year, he required corticosteroids to prevent wheezing and coughing at night; however, he was unable to reduce his smoking to less than one pack of cigarettes per day. When seen 3 months prior to his terminal episode, he had significantly reduced $\mathrm{FEV}_{1}$ and FVC with no response to bronchodilators. He awoke one evening complaining to his wife about coughing and worsening shortness of breath. He was taken to the emergency room where he was found to have an acute exacerbation of obstructive airway disease. He was admitted to the hospital. At the patient's request, no mechanical ventilation was employed, and he died 12 hours later in respiratory arrest. 


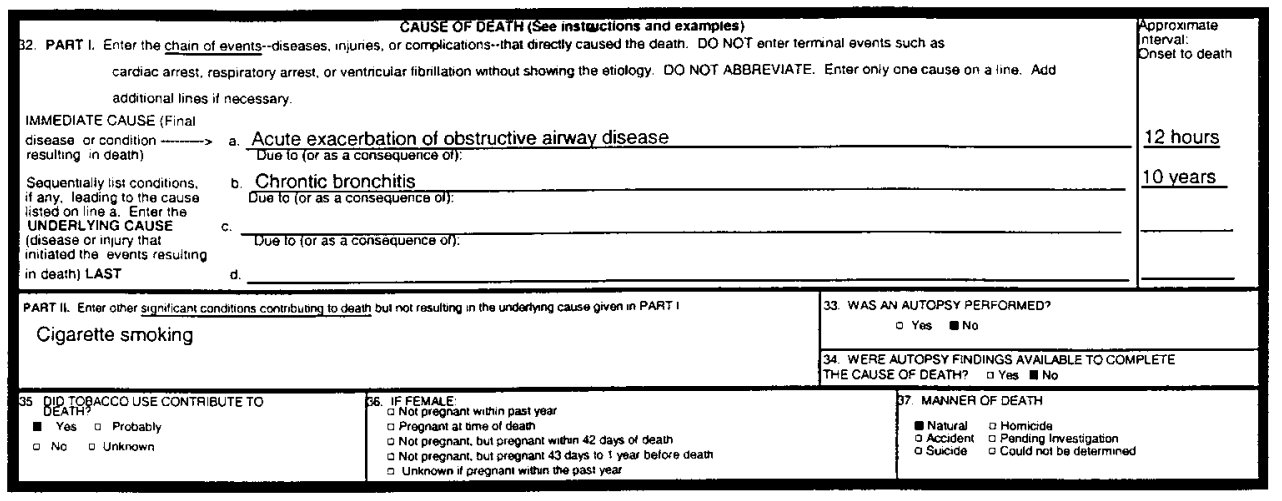

Notes on death certification:

In this case, respiratory arrest is considered a mechanism of death, and it would not be listed as the Immediate Cause of Death.

\section{Case history no. 8}

A 75-year-old female had a 15-year history of noninsulin-dependent diabetes mellitus, a 13-year history of mild hypertension treated with thiazide diuretics, and an uncomplicated myocardial infarction 6 years prior to the present illness. She was found disoriented in her apartment and brought to the hospital. On admission she was noted to be unresponsive, without focal neurologic signs, and severely dehydrated with a blood pressure of 90/60. Initial laboratory tests disclosed severe hyperglycemia, hyperosmolarity, azotemia, and mild ketosis without acidosis. A diagnosis of hyperosmolar nonketotic coma was made.

The patient was vigorously treated with fluids, electrolytes, insulin, and broad-spectrum antibiotics, although no source for infection was documented. Within 72 hours, the patient's hyperosmolar, hyperglycemic state was resolved. However, she remained anuric with progressive azotemia. Attempts at renal dialysis were unsuccessful, and the patient died on the 8th hospital day in severe renal failure. 


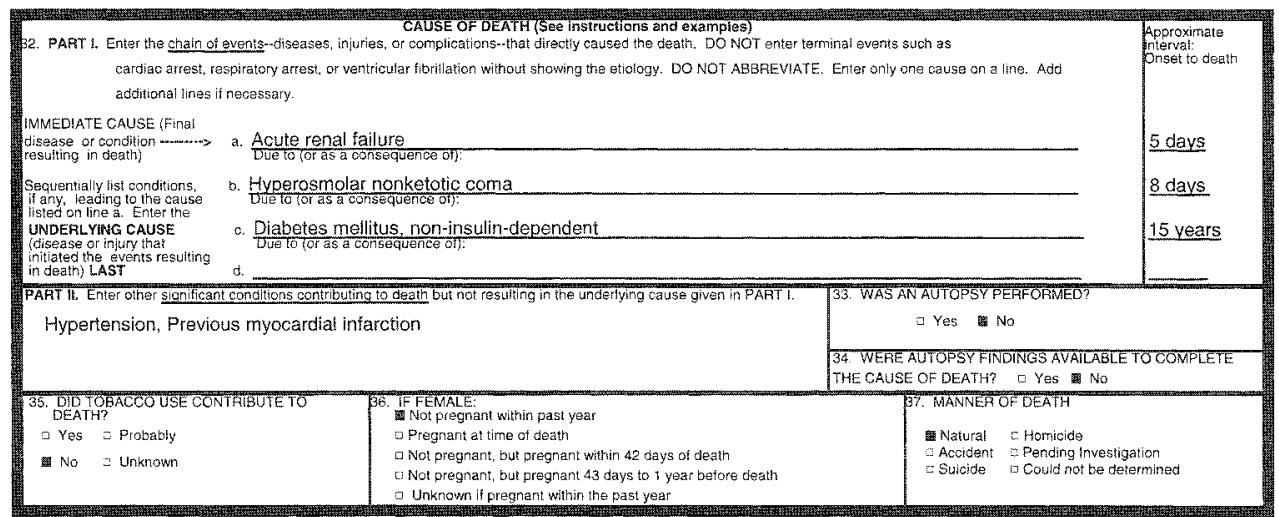

Notes on death certification:

In this case, hypertension and a previous myocardial infarction would both be considered factors that contributed to the death. However, they would not be in the direct causal sequence of Part I, so they would be placed in Part II.

\section{Case history no. 9}

This 53-year-old male was admitted to the hospital following 2 days of intermittent midepigastric and left-sided chest pain. The pain radiated to his left arm and was accompanied by nausea and vomiting. He gave a history that included 2 years of occasional chest discomfort, a near syncopal episode 6 months prior, hypertension, a 30-year history of one-packper-day cigarette smoking, congenital blindness, and insulin-dependent diabetes mellitus. He was noted to be markedly obese and to have severe hypercholesterolemia.

At the time of admission, his enzyme studies were normal, but the EKG suggested myocardial ischemia. Two days later, he experienced an episode of severe chest pain that did not respond to nitroglycerin and was accompanied by ST-segment elevation. A cardiac catheterization demonstrated severe multivessel coronary artery stenosis. He underwent quadruple coronary artery bypass surgery. Shortly, after being taken off the cardiopulmonary bypass machine, he went into cardiac arrest. As resuscitation was being attempted by open cardiac massage, a rupture developed in his left ventricular wall that resulted in rapid exsanguination and death. 


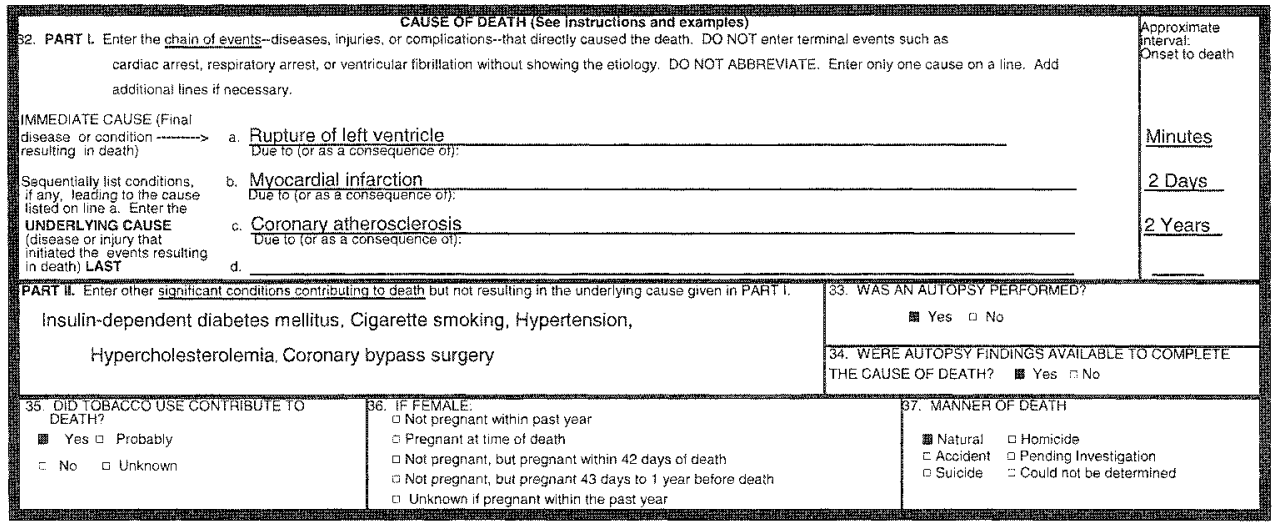

\section{Notes on death certification:}

In this case, insulin-dependent diabetes mellitus, cigarette smoking, hypertension, and hypercholesterolemia would all be considered factors that contributed to the death. However, they would not be in the direct causal sequence of Part I, so they would be placed in Part II. The surgery probably played a role in death but did not cause the coronary artery disease, so it is also listed in Part II.

\section{Case history no. 10}

A 1,480-gram male infant was born at 32-weeks gestation to a 20-year-old primiparous woman. Newborn screening found elevated levels of immunoreactive trypsinogen in the blood. The infant developed respiratory distress syndrome and required mechanical ventilation for 7 days. Despite receiving adequate calories for growth, the infant gained weight poorly and had persistent diarrhea. Steatorrhea was confirmed upon microscopic examination. Results from a sweat chloride test given on the 21 st day after birth were negative, but the patient had an elevated sweat chloride concentration of 85 millimoles per liter when the test was repeated at 35 days of age. On the 37th day after birth, the infant became lethargic and was noted to be edematous. Escherichia coli was cultured from the infant's cerebral spinal fluid, total serum proteins were reported to be low, and clotting studies were prolonged. The infant died at 45 days of age despite appropriate life-saving efforts. Gross autopsy confirmed the clinical impression of cystic fibrosis. 


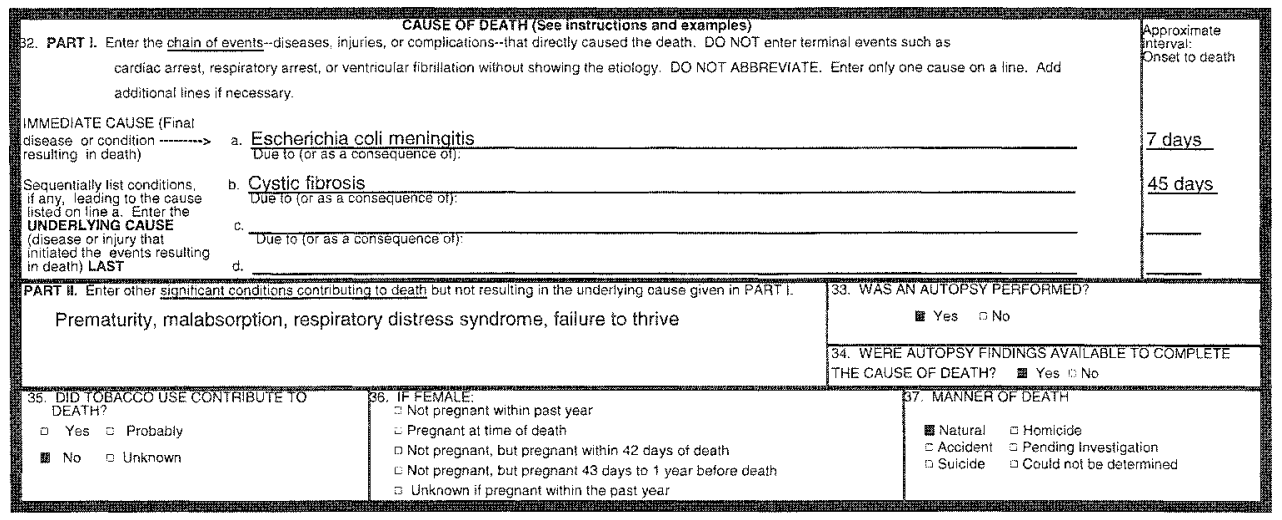

Notes on death certification:

In this case, prematurity, malabsorption, respiratory distress syndrome, and failure to thrive would all be considered factors that contributed to the death. However, they would not be in the direct causal sequence of Part I, so they would be placed in Part II.

\section{Case history no. 11}

A 30-year-old, gravida-six, para-five, with a history of gestational hypertension, reported to the emergency room at 36 weeks gestation with complaints of abdominal cramping and light vaginal bleeding during the past 12 hours. At time of first assessment, fetal heart tones were detected. The uterus was tense, irritable, and tender. The mother was hypotensive with tachycardia. A presumptive diagnosis of abruptio placenta was made, and an emergency cesarean section was performed under general anesthesia. The baby was stillborn. The mother continued to bleed from her uterus and phlebotomy sites and went into profound shock secondary to disseminated intravascular coagulation. Despite administration of blood and clotting factors, intravascular pressure could not be maintained, and the mother died on the operating table. Maternal autopsy confirmed the clinical diagnosis.

A death certificate would be completed for the mother and a fetal death report for the fetus. The cause of fetal death is reported using a different format. Please refer to the Medical Examiners' and Coroners' Handbook on Death Registration and Fetal Death Reporting for further information. 
Maternal death certificate:

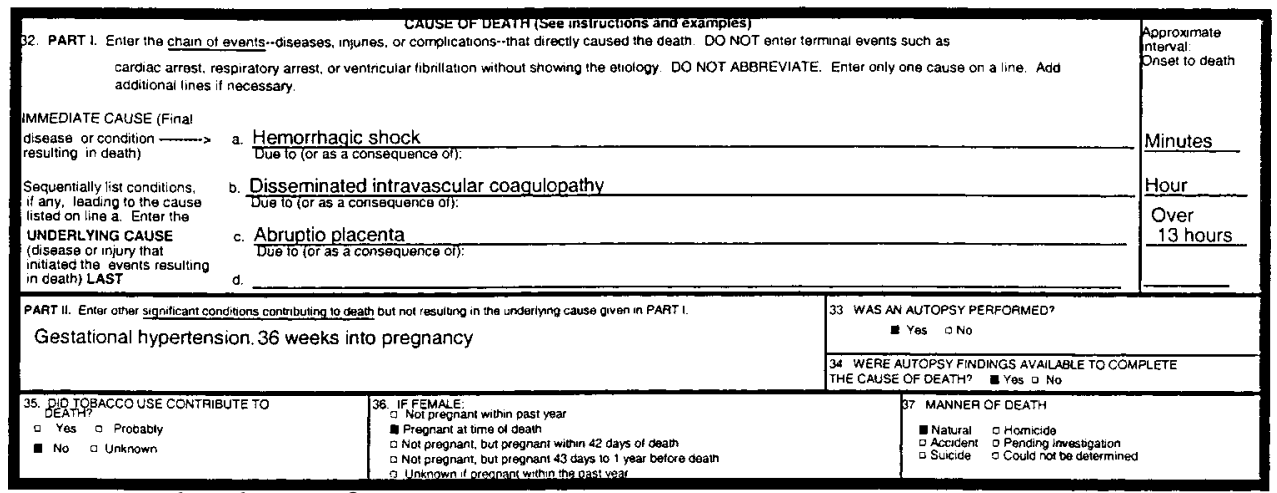

Notes on death certification:

In this case, gestational hypertension would be considered a factor that contributed to the death. However, it would not be in the direct causal sequence of Part I, so it would be placed in Part II. 
Fetal death report:

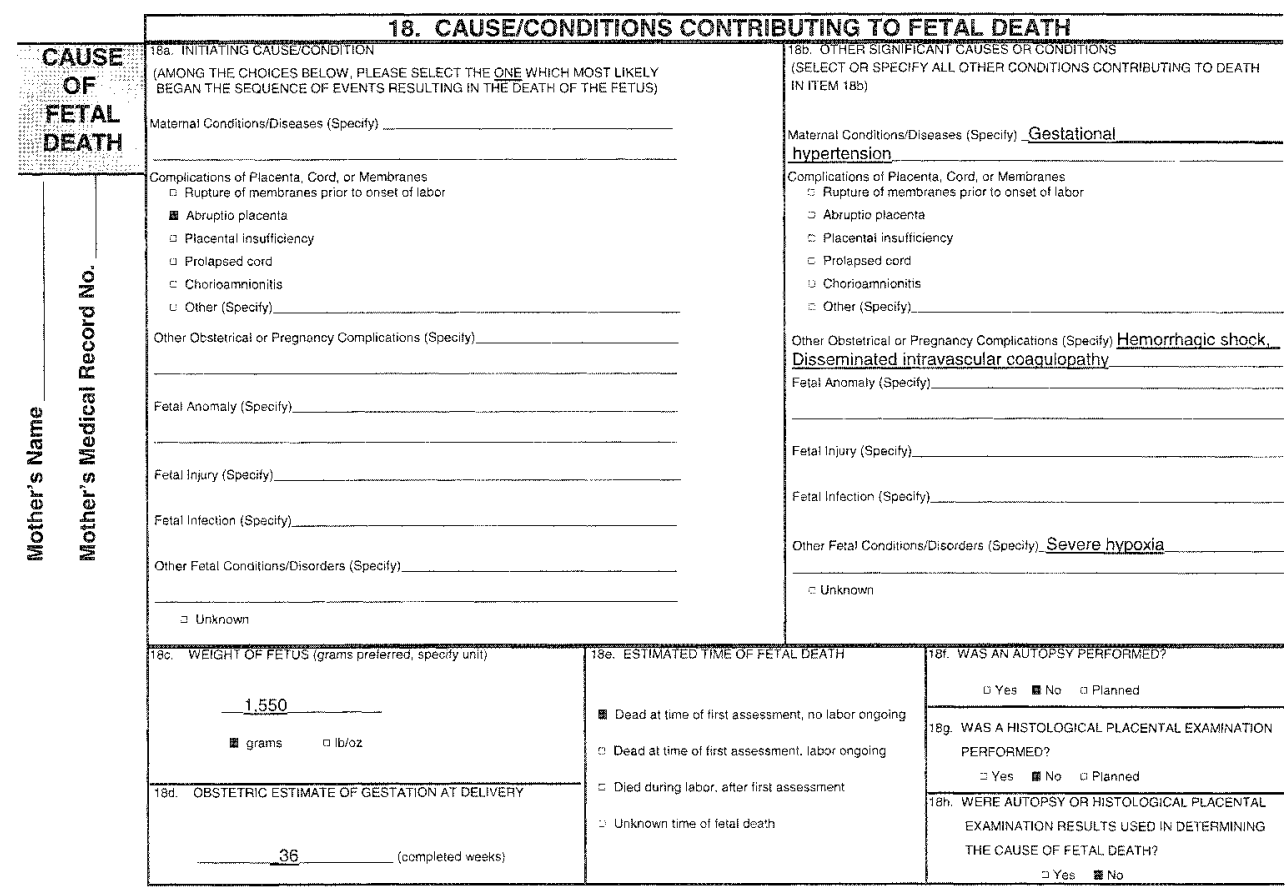

\section{Case history no. 12}

A 92-year-old male was found dead in bed. He had no significant medical history. Autopsy disclosed minimal coronary disease and generalized atrophic changes commonly associated with aging. No specific cause of death was identified. Toxicology was negative. 


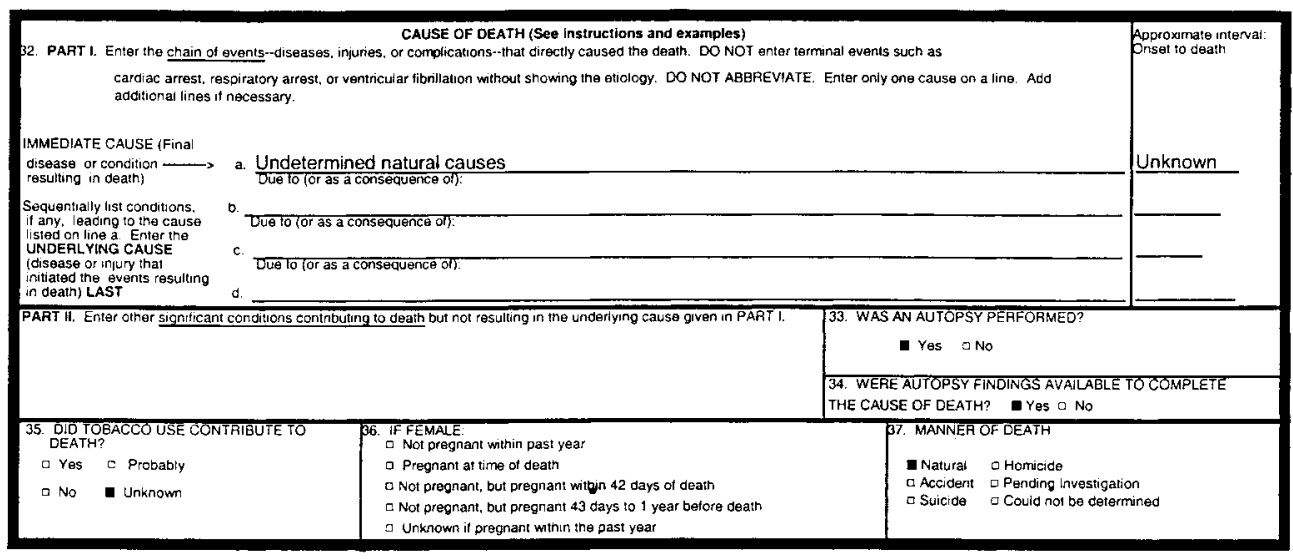

Note: In some cases, no overwhelming cause presents itself. It is acceptable to indicate that a thorough investigation was performed; however, no cause could be determined.

\section{Case history no. 13}

A 102-year-old female was brought to the hospital because her word combinations were not comprehensible. However, at admission, her sentences were lucid. She was placed on blood anticoagulants. She had a history of arthritis, hypertension, blocked arteries, coronary thrombosis (25 years before), stroke (10 years before), periodic TIAs (8-year period), and congestive heart failure (hospitalized 6 years before). On the fourth day in the hospital, a colonoscopy indicated internal bleeding, so the anticoagulant was discontinued. She was released from the hospital after 7 days. After discharge, language and motor skills were impaired although functioning was better earlier in the day; moreover, her leg coloration started changing. After a week at home, the woman was re-admitted to the hospital following a spell of vomiting. Vascular imaging indicated that circulation was blocked at the groin, there was no improvement in language, ability to eat and keep food down deteriorated, and heart rate periodically was arrythmic with periods of third-degree heart block. After a week of hospitalization, she was sent home under hospice care and died 2 days later. Her attending physician completed the death certificate. 


\begin{tabular}{|c|c|c|c|}
\hline \multicolumn{3}{|c|}{ 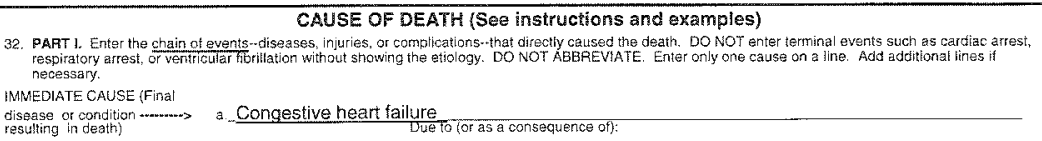 } & $\begin{array}{l}\text { Approximate interval: } \\
\text { Onset to death }\end{array}$ \\
\hline \multicolumn{3}{|c|}{ 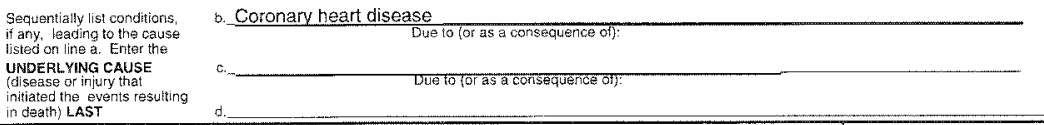 } & _- 25 years \\
\hline \multicolumn{2}{|c|}{$\begin{array}{l}\text { PART Il. Enter other signlilicant conditions contributing to death but not resulting in the underlying cause given in PART } \\
\text { Hypertension, atrial fibrillation }\end{array}$} & $\begin{array}{l}\text { 33. WAS AN AUTOPSY PERFF } \\
\text { U YES } \text {. NO } \\
\text { 34. WEREE AUTOPSY FINDINS } \\
\text { COMPLETE THE CAUSE OF D }\end{array}$ & \\
\hline 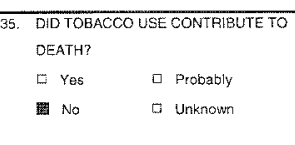 & $\begin{array}{l}\text { 36. IF FEMALE: } \\
\text { Not pregnant within past year } \\
\square \text { Pregnant at time of death } \\
\square \text { Not pregnant, but prognant within } 42 \text { days of death } \\
\square \text { Not prognant, but pregnant } 43 \text { days to } 1 \text { year before death } \\
\square \text { Unknown if pregnant within the past year }\end{array}$ & 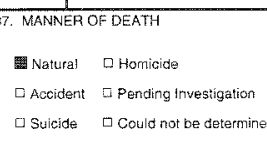 & \\
\hline
\end{tabular}

\section{Common problems in death certification}

Often several acceptable ways of writing a cause-of-death statement exist. Optimally, a certifier will be able to provide a simple description of the process leading to death that is etiologically clear and be confident that this is the correct sequence of causes. However, realistically, description of the process is sometimes difficult because the certifier is not certain.

In this case, the certifier should think through the causes about which he/she is confident and what possible etiologies could have resulted in these conditions. The certifier should select the causes that are suspected to have been involved and use words such as "probable" or "presumed" to indicate that the description provided is not completely certain. If the initiating condition reported on the death certificate could have arisen from a pre-existing condition, but the certifier cannot determine the etiology, he/she should state that the etiology is unknown, undetermined, or unspecified, so it is clear that the certifier did not have enough information to provide even a qualified etiology. Reporting a cause of death as unknown should be a last resort.

The elderly decedent should have a clear and distinct etiological sequence for cause of death, if possible. Terms such as senescence, infirmity, old age, and advanced age have little value for public health or medical research. Age is recorded elsewhere on the certificate. When a number of conditions resulted in death, the physician should choose the single sequence that, in his or her opinion, best describes the process leading to death, and place any other pertinent conditions in Part II. "Multiple system failure" could be included in Part II, but the systems need to be specified to ensure that the information is captured. If after careful 
consideration, the physician cannot determine a sequence that ends in death, then the medical examiner or coroner should be consulted about conducting an investigation or providing assistance in completing the cause of death.

The infant decedent should have a clear and distinct etiological sequence for cause of death, if possible. "Prematurity" should not be entered without explaining the etiology of prematurity. Maternal conditions may have initiated or affected the sequence that resulted in infant death, and such maternal causes should be reported in addition to the infant causes on the infant's death certificate (e.g., hyaline membrane disease due to prematurity, 28 weeks due to placental abruption due to blunt trauma to mother's abdomen).

When Sudden Infant Death Syndrome (SIDS) is suspected, a complete investigation should be conducted, typically by a medical examiner or coroner. If the infant is under 1 year of age, no cause of death is determined after scene investigation, review of clinical history, and a complete autopsy. The death then can be reported as SIDS. Refer to the Medical Examiners' and Coroners' Handbook on Death Registration and Fetal Death Reporting for more information.

Most certifiers will find themselves, at some point, in the circumstance in which they are unable to provide a simple description of the process of death. In this situation, the certifier should try to provide a clear sequence, qualify the causes about which he/she is uncertain, and be able to explain the certification chosen.

When processes such as the following are reported, additional information about the etiology should be reported:

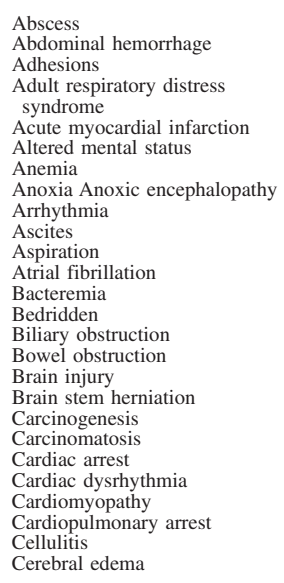

Abdominal hemorrhage

Adhesion

Adult respiratory distres

Anemia

Arrhythmia

Ascites

Atrial fibrillation

Bacteremia

Biliary obstruction

Brain injury

Carcinomatosis

Cardiac dysrbythm

Cardiomyopathy

Cellulitis

Cerebral edema

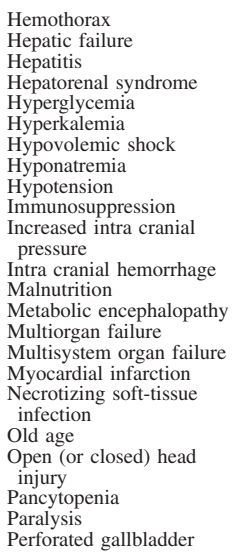

Peritoniti

Pleural effusions Pneumonia

Pulmonary arrest

Pulmonary edema

Pulmonary embolism

Penal falure

Renal failure

Respiratory arrest

Seizures

Septic shock

Shock

Shock

Subdural hematom

Subarachnoid

hemorrhage

Sudden death

Thrombocytopenia

Uncal herniation

Urinary tract infection

Ventricular fibrillation

Ventricular tachycardi

Volume depletion 
If the certifier is unable to determine the etiology of a process such as those shown above, the process must be qualified as being of an unknown, undetermined, probable, presumed, or unspecified etiology so it is clear that a distinct etiology was not inadvertently or carelessly omitted.

The following conditions and types of death might seem to be specific or natural. However, when the medical history is examined further it may be found to be complications of an injury or poisoning (possibly occurring long ago). Such cases should be reported to the medical examiner or coroner.

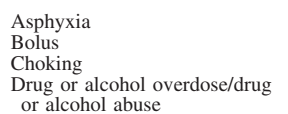

or alcohol abuse

\section{Additional resources}

In addition to the series of handbooks, additional resources include manuals, guidelines, and Web sites (7-15). Resources on completing death certificates should be kept with or near blank death certificates for easy reference. Additional copies of government-produced resources are available from the State vital statistics offices, the National Center for Health Statistics, and the Internet at http://www.cdc.gov/nchs (under vital statistics, mortality, writing cause-of-death statements). 


\section{Completing Other Items on the Death Certificate}

\section{These instructions pertain to the 2003 revision of the U.S. Standard Certificate of Death.}

\section{NAME OF DECEDENT: For use by physician or institution}

The left-hand margin of the certificate contains a line where the physician or hospital can write in the name of the decedent. This allows the hospital to assist in completing the death certificate before the body is removed by the funeral director. However, because the funeral director is responsible for completion of the personal information about the decedent and because the hospital frequently does not have the complete legal name of the decedent, the hospital or physician should enter the name they have for the decedent in this item. The funeral director will then enter the full legal name in item 1 .

\section{PLACE OF DEATH (Check only one; see instructions)}

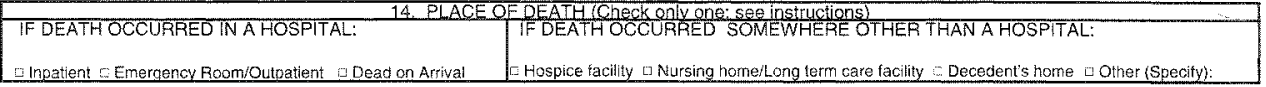

Check the type of place where the decedent was pronounced dead.

Hospital deaths

If the decedent was pronounced dead in a hospital, check the box indicating the decedent's status at the hospital: Inpatient, Emergency Room/ Outpatient (ER) or Dead on Arrival (DOA). Hospitals are licensed institutions providing patients diagnostic and therapeutic services by a medical staff.

Nonhospital deaths

If the decedent was pronounced dead somewhere else, check the box indicating whether pronouncement occurred at a Hospice facility, Nursing home/Long-term care facility, Decedent's home, or other location.

Hospice facility refers to a licensed institution providing hospice care (e.g., palliative and supportive care for the dying), not to hospice care that might be provided in a number of different settings, including a patient's home. 
If death was pronounced at a licensed long-term care facility, check the box that indicates Nursing home/Long term care facility. A long-term care facility is not a hospital, but provides patient care beyond custodial care (e.g., nursing home, skilled nursing facility, long-term care facilities, convalescent care facility, extended care facility, intermediate care facility, residential care facility, congregate care facility).

If death was pronounced in the decedent's home, check the box that indicates decedent's home. A decedent's home includes independent living units including private homes, apartments, bungalows, and cottages.

If death was pronounced at a licensed ambulatory/surgical center, orphanage, prison ward, public building, birthing center, facilities offering housing and custodial care, but not patient care (e.g., board and care home, group home, custodial care facility, foster home), check "Other (Specify)." If "Other (Specify)" is checked, specify where death was legally pronounced, such as a prison ward, physician's office, the highway where a traffic accident occurred, a vessel, orphanage, group home, or at work.

If the place of death is unknown, but the body is found in a State, enter the place where the body is found as the place of death.

\section{FACILITY NAME (If not an institution, give street and number)}

\section{Institution deaths}

If the death occurred in a hospital, enter the full name of the hospital.

If death occurred en route to or on arrival at a hospital, enter the full name of the hospital. Deaths that occur in an ambulance or emergency squad vehicle en route to a hospital fall in this category.

If the death occurred in another type of institution such as a nursing home, enter the name of the institution where the decedent died.

\section{Noninstitution deaths}

If the death occurred at home, enter the house number and street name.

If the death occurred at some place other than those described above, enter the number and street name of the place or building (if at a building) where the decedent died.

If the death occurred on a moving conveyance, enter the name of the vessel, for example, S.S. Olive Seas (at sea) or "Eastern Airlines Flight 296 (in flight)." 


\section{CITY OR TOWN, STATE, AND ZIP CODE}

Enter the name of the city, town, village, or location, State, and zip code where death occurred.

\section{COUNTY OF DEATH}

Enter the name of the county of the institution or address given in item 15 where death occurred. If the death occurred on a moving conveyance in the United States and the body is first removed from the conveyance in this State, complete a death certificate and enter as the place of death the address where the body was first removed from the conveyance.

If the death occurred on a moving conveyance in international waters, international airspace, or in a foreign country or its airspace, and the body is first removed from the conveyance in this State, register the death in this State, but enter the actual place of death insofar as can be determined.

These items are used to identify the place of death to determine who has jurisdiction for deaths that legally require investigation by a medical examiner or coroner. These items are also used for research and statistics comparing hospital and nonhospital deaths. Valuable information is also provided for health planning and the utilization of health facilities.

\section{Items on when death occurred}

Items 24 and 25 and 29-31 should always be completed. If the facility uses a separate pronouncer or other person to indicate that death has taken place with another person more familiar with the case completing the remainder of the medical portion of the death certificate, the pronouncer completes Items 24-28. In all other cases, the certifier completes Items 24, 25, 29-37, and 45-49, and Items 26-28 are left blank.

\section{DATE PRONOUNCED DEAD (Month, Day, and Year)}

Enter the exact month, day, and four-digit year that the decedent was pronounced dead. Complete this item even when it is the same as Item 29, the actual or presumed date.

Enter the full name of the month-January, February, March, etc. Do not use a number or abbreviation to designate the month.

This is used to identify the date the decedent was legally pronounced dead. This information is very helpful in those cases where a body of a person who has been dead for some time is found and the death is pronounced by a medical examiner or coroner. 


\section{TIME PRONOUNCED DEAD}

Enter the exact time (hour and minute using a 24-hour clock) the decedent was pronounced dead according to local time. If daylight saving time is the official prevailing time where death occurs, it should be used to record the time of death. Be sure to indicate the time using a 24-hour clock.

\begin{tabular}{|l|l|}
\hline $\mathbf{2 4 - h o u r ~ c l o c k}$ & 12-hour clock \\
\hline $\begin{array}{l}\text { (medical facilities); } \\
2400 \text { (military facilities) }\end{array}$ & 12 midnight \\
\hline 0100 & $1: 00$ a.m. \\
\hline 0200 & $2: 00$ a.m. \\
\hline 0300 & $3: 00$ a.m. \\
\hline 0400 & $4: 00$ a.m. \\
\hline 0500 & $5: 00$ a.m. \\
\hline 0600 & $6: 00$ a.m. \\
\hline 0700 & $7: 00$ a.m. \\
\hline 0800 & $8: 00$ a.m. \\
\hline 0900 & $9: 00$ a.m. \\
\hline 1000 & $10: 00$ a.m \\
\hline 1100 & $11: 00$ a.m. \\
\hline 1200 & 12 noon \\
\hline 1300 & $1: 00$ p.m. \\
\hline 1400 & $2: 00$ p.m. \\
\hline 1500 & $3: 00$ p.m. \\
\hline 1600 & $4: 00$ p.m. \\
\hline 1700 & $5: 00$ p.m. \\
\hline 1800 & $6: 00$ p.m. \\
\hline 1900 & $7: 00$ p.m. \\
\hline 2000 & $8: 00$ p.m. \\
\hline 2100 & $9: 00$ p.m. \\
\hline 2200 & $10: 00$ p.m. \\
\hline 2300 & $11: 00$ p.m \\
\hline
\end{tabular}

A death that occurs at 2400 or 0000 midnight belongs to the start of the new day. One minute after 12 midnight is entered as 0001 of the new day.

If the exact time of death is unknown, the time should be approximated by the person who pronounces the body dead. "Approx" should be placed before the time.

\section{6-28 PRONOUNCING PHYSICIAN ONLY}

Items 26-28 are to be completed only when the physician responsible for completing the medical certification of cause of death is not available at the time of death to certify the cause of death and when State law provides for a pronouncing physician. In this situation, a pronouncing physician is the person who determines that the decedent is legally dead, but who was not in charge of the patient's care for the illness or condition that resulted 
in death. This hospital physician certifies to the fact and time of death (Items 24 and 25) and signs and dates the death certificate (Items 26-28) so the body can be released to the funeral director when the attending physician is not available. The attending physician is still responsible for completing the cause-of-death section (Item 32). See Part II of this handbook for a more detailed discussion of the completion of Item 32 .

COMPLETE ITEMS 26-28 ONLY WHEN CERTIFYING PHYSICIAN IS NOT AVAILABLE AT TIME OF DEATH CERTIFY CAUSE OF DEATH

\section{SIGNATURE OF PERSON PRONOUNCING DEATH (Only when applicable)}

Obtain the signature and the degree or title of the physician who pronounces death in ink. This physician certifies to the time, date, and place of death only. Rubber stamps or facsimile signatures are not permitted on paper certificates. Jurisdictions with electronic death certificates may have other ways to authenticate the certification than by using a signature.

\section{LICENSE NUMBER (Only when applicable)}

Enter the State license number of the physician who pronounces death.

\section{DATE SIGNED (Month, Day, and Year) (Only when applicable)}

Enter the exact month, day, and year that the pronouncing physician signs the certificate. Do not use a number to designate the month.

IF THE ATTENDING PHYSICIAN IS AVAILABLE TO CERTIFY THE FACT OF DEATH, ITEMS 26-28 SHOULD NOT BE COMPLETED; IF AVAILABLE, THE ATTENDING PHYSICIAN SHOULD COMPLETE ITEMS 24, 25, 29-37, AND 45-49 AS BOTH PRONOUNCING AND CERTIFYING PHYSICIAN.

This information is useful for the quality control program indicating that the medical certification was provided by the attending physician.

Items 24 and 25 must be completed by the person who pronounces deaththe pronouncing physician, pronouncing/certifying physician, or medical examiner or coroner.

\section{ACTUAL OR PRESUMED DATE OF DEATH (Month, Day, and Year)}

Enter the exact month, day, and year that death occurred.

Enter the full name of the month-January, February, March, etc. Do not use a number or abbreviation to designate the month. 
Pay particular attention to the entry of month, day, and year when the death occurs around midnight or December 31. Consider a death at midnight to have occurred at the beginning of the next day rather than the end of the previous day. For example, the date for a death that occurs at 11:59 p.m. or 2359 on December 31 should be recorded as December 31 while those occurring the next minute 0000 should be recorded as January 1.

If the exact date of death is unknown, it should be approximated by the person completing the medical certification. "Approx" should be placed before the date. If date cannot be determined by approximating, the date found should be entered and identified as such.

This item is used in conjunction with the hour of death to establish the exact time of death of the decedent. Epidemiologists also use date of death in conjunction with the cause-of-death section for research on intervals between injuries, onset of conditions, and death.

\section{ACTUAL OR PRESUMED TIME OF DEATH}

Enter the exact time (hour and minute using a 24-hour clock) of death according to local time. If daylight saving time is the official prevailing time where death occurs, it should be used to record the time of death. Be sure to indicate the time using a 24-hour clock.

\begin{tabular}{|l|l|}
\hline $\mathbf{2 4 - h o u r ~ c l o c k}$ & $\mathbf{1 2 - h o u r}$ clock \\
\hline $\begin{array}{l}\text { 0000 (medical facilities); } \\
2400 \text { (military facilities) }\end{array}$ & 12 midnight \\
\hline 0100 & $1: 00$ a.m. \\
\hline 0200 & $2: 00$ a.m. \\
\hline 0300 & $3: 00$ a.m. \\
\hline 0400 & $4: 00$ a.m. \\
\hline 0500 & $5: 00$ a.m. \\
\hline 0600 & $6: 00$ a.m. \\
\hline 0700 & $7: 00$ a.m. \\
\hline 0800 & $8: 00$ a.m. \\
\hline 0900 & $9: 00$ a.m. \\
\hline 1000 & $10: 00$ a.m \\
\hline 1100 & $11: 00$ a.m. \\
\hline 1200 & 12 noon \\
\hline 1300 & $1: 00$ p.m. \\
\hline 1400 & $2: 00$ p.m. \\
\hline 1500 & $3: 00$ p.m. \\
\hline 1600 & $4: 00$ p.m. \\
\hline 1700 & $5: 00$ p.m. \\
\hline 1800 & $6: 00$ p.m. \\
\hline 1900 & $7: 00$ p.m. \\
\hline 2000 & $8: 00$ p.m. \\
\hline 2100 & $9: 00$ p.m. \\
\hline 2200 & $10: 00$ p.m. \\
\hline 2300 & $11: 00$ p.m \\
\hline
\end{tabular}


A death that occurs at 2400 or 0000 midnight belongs to the start of the new day. One minute after 12 midnight is entered as 0001 of the new day.

If the exact time of death is unknown, the time should be approximated by the person who certifies the death. "Approx" should be placed before the time.

This item establishes the exact time of death, which is important in inheritance cases when there is a question of who died first. This is often important in the case of multiple deaths in the same family.

\section{WAS MEDICAL EXAMINER OR CORONER CONTACTED?}

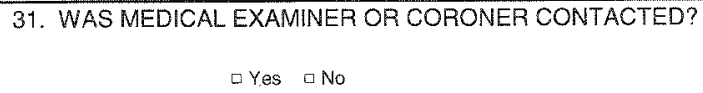

Enter "Yes" if the medical examiner or coroner was contacted in reference to this case. Otherwise enter "No." Do not leave this item blank.

In cases of accident, suicide, or homicide, the medical examiner or coroner must be notified.

This item records whether the medical examiner or coroner was informed when the circumstances require such action. In such cases, the physician must ensure that this is done.

\section{CAUSE OF DEATH}

Detailed instructions for this item, together with case records, are contained in the section on Medical Certification of Death in this handbook.

These items are to be completed by the attending physician or medical examiner or coroner certifying or reporting his or her opinion on the cause of death.

Part I. Enter the chain of events-diseases, injuries, or complications-that directly caused the death. DO NOT enter terminal events such as cardiac arrest, respiratory arrest, or ventricular fibrillation without showing the etiology. DO NOT ABBREVIATE. Enter only one cause on a line. Add additional lines if necessary.

The cause of death means the disease, abnormality, injury, or poisoning that caused the death, not the mechanism of death, such as cardiac or respiratory arrest, shock, or heart failure. 
In Part I, the immediate cause of death (final disease or condition resulting in death) is reported on line (a). Antecedent conditions, if any, that gave rise to the cause are reported on lines (b), (c), and (d). The underlying cause (disease or injury that initiated events resulting in death) should be reported on the last line used in Part I. No entry is necessary on lines (b), (c), and (d) if the immediate cause of death on line (a) describes completely the sequence of events. ONLY ONE CAUSE SHOULD BE ENTERED ON A LINE.

Provide the best estimate of the interval between the onset of each condition and death. Do not leave the space for the interval blank; if unknown, so specify.

Part II. Enter other significant conditions contributing to death but not resulting in the underlying cause given in Part $I$.

In Part II, enter other important diseases or conditions that contributed to death but did not result in the underlying cause of death given in Part I.

Cause of death is the most important statistical research item on the death certificate. It provides medical information that serves as a basis for describing trends in human health and mortality and for analyzing the conditions leading to death. Mortality statistics provide a basis for epidemiological studies that focus on leading causes of death by age, race, or sex (for example, HIV, heart disease, and cancer). They also provide a basis for research in disease etiology and evaluation of diagnostic techniques, which in turn lead to improvements in patient care.

All conditions reported are important and are analyzed. For example, analyses may examine associations between conditions reported on the same death certificates such as types of conditions reported in combination with hepatitis.

\section{WAS AN AUTOPSY PERFORMED?}

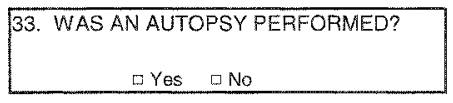

Enter "Yes" if a partial or complete autopsy was performed. Otherwise enter "No."

An autopsy is important in giving additional insight into the conditions that lead to death. This additional information is particularly important in arriving at the immediate and underlying causes when the cause is not immediately clear. 


\title{
34. WERE AUTOPSY FINDINGS AVAILABLE TO COMPLETE THE CAUSE OF DEATH?
}

\author{
34. WERE AU:OPSY FINDINGS AVAILABLE TO \\ COMPLETE THE GAUSE OF DEATH? $\square$ YES $\square$ NO
}

Enter "Yes" if the autopsy findings were available at the time that cause of death was determined. Otherwise enter "No." Leave this item blank if no autopsy was performed.

This information assists in determining whether, for the 9 percent of cases for which an autopsy is done, the information was available to assist in determining the cause of death. Knowing whether the autopsy results were available for determining the cause of death gives insight into the quality of the cause-of-death data.

\section{DID TOBACCO USE CONTRIBUTE TO DEATH?}

Check "Yes" if, in the physician's opinion, any use of tobacco or tobacco exposure contributed to death. For example, tobacco use may contribute to deaths due to emphysema or lung cancer. Tobacco use also may contribute to some heart disease and cancers of the head and neck. Tobacco use should also be reported in deaths due to fires started by smoking. Check "Yes," if in the physician's clinical judgment, tobacco use contributed to this particular death. Check "No," if, in the physician's opinion, the use of tobacco did not contribute to death.

\section{IF FEMALE, WAS DECEDENT PREGNANT AT TIME OF DEATH OR WITHIN PAST YEAR?}

If the decedent is a female, check the appropriate box in Item 36. If the decedent is a male, leave the item blank. If the female is either too old or too young to be fecund, check the "Not pregnant within the past year" box.

This information is important in determining the scale of mortality amongst this population and will be of assistance with maternal mortality review programs.

\section{MANNER OF DEATH}

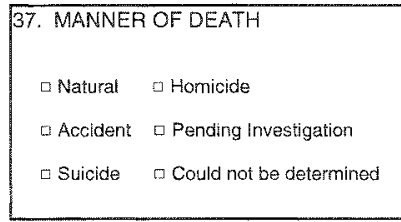


Complete this item for all deaths. Check the box corresponding to the manner of death. Deaths not due to external causes should be identified as "Natural." Usually, these are the only types of deaths a physician will certify.

Indicate "Pending investigation" if the manner of death cannot be determined to be accident, homicide, or suicide within the statutory time limit for filing the death certificate. This should be changed later to one of the other terms.

Indicate "Could not be determined" ONLY when it is impossible to determine the manner of death.

In cases of accidental death, this information is used to justify the payment of double indemnity on life insurance policies. It is also used to obtain a more accurate determination of cause of death.

All deaths due to external causes must be referred to the medical examiner or coroner. If the manner of death checked in Item 37 was anything other than natural, Items 38-44 must be completed. If a situation ever arises where the physician must complete the cause, manner, and circumstances (Items 32, 37, and 38-44) of death in an accidental case, please refer to the Medical Examiners' and Coroners' Handbook on Death Registration and Fetal Death Reporting. Case histories with properly completed death certificates are also included in that handbook.

The National Association of Medical Examiners have put together a guide on how manner of death may be determined (6). In certain cases, there is a conflict between the manner of death preferred by the medical examiner community and the disease classification. As a result, it is important to specify the circumstances involved so that both communities are able to make use of the information.

\section{8-44 ACCIDENT OR INJURY-To be filled out in all cases of deaths due to injury or poisoning}

Complete these items in cases where injury caused or contributed to the death. All deaths resulting from injury must be reported to a medical examiner or coroner, who will usually certify to the cause of death. However, there may be instances in which a medical examiner or coroner will not assume jurisdiction and the attending physician will certify to an accidental death. In these cases when the manner of death is anything other than natural, the attending physician is to complete Items 38-44. 


\section{DATE OF INJURY (Month, Day, and Year)}

Enter the exact month, day, and year that the injury occurred. Enter the full name of the month-January, February, March, etc. Do not use a number or abbreviation to designate the month.

The date of injury may not necessarily be the same as the date of death.

Estimates may be provided with "Approx" placed before the date.

\section{TIME OF INJURY}

Enter the exact time (hour and minute using a 24-hour clock) when the injury occurred, according to local time. If daylight saving time is the official prevailing time where death occurs, it should be used to record the time of death. Be sure to indicate the time using a 24-hour clock.

\begin{tabular}{|l|l|}
\hline 24-hour clock & 12-hour clock \\
\hline $\begin{array}{l}\text { 0000 (medical facilities); } \\
2400 \text { (military facilities) }\end{array}$ & 12 midnight \\
\hline 0100 & $1: 00$ a.m. \\
\hline 0200 & $2: 00$ a.m. \\
\hline 0300 & $3: 00$ a.m. \\
\hline 0400 & $4: 00$ a.m. \\
\hline 0500 & $5: 00$ a.m. \\
\hline 0600 & $6: 00$ a.m. \\
\hline 0700 & $7: 00$ a.m. \\
\hline 0800 & $8: 00$ a.m. \\
\hline 0900 & $9: 00$ a.m. \\
\hline 1000 & $10: 00$ a.m \\
\hline 1100 & $11: 00$ a.m. \\
\hline 1200 & 12 noon \\
\hline 1300 & $1: 00$ p.m. \\
\hline 1400 & $2: 00$ p.m. \\
\hline 1500 & $3: 00$ p.m. \\
\hline 1600 & $4: 00$ p.m. \\
\hline 1700 & $5: 00$ p.m. \\
\hline 1800 & $6: 00$ p.m. \\
\hline 1900 & $7: 00$ p.m. \\
\hline 2000 & $8: 00$ p.m. \\
\hline 2100 & $9: 00$ p.m. \\
\hline 2200 & $10: 00$ p.m. \\
\hline 2300 & $11: 00$ p.m \\
\hline
\end{tabular}

If the exact time of death is unknown, the time should be approximated by the person who certifies the death. "Approx" should be placed before the time.

The date of injury may differ from the date of death. 


\section{PLACE OF INJURY (e.g., Decedent's home, construction site, restaurant, wooded area)}

Enter the general type of place (such as restaurant, vacant lot, baseball field, construction site, office building, or decedent's home) where the injury occurred. DO NOT enter firm or organization names. (For example, enter "factory," not "Standard Manufacturing, Inc.")

\section{INJURY AT WORK?}

41. INJURYAT WORK?

O Yes D No

Complete if anything other than natural disease is mentioned in Part I or Part II of the medical certification (Item 32), including homicides, suicides, and accidents or if anything other than "Natural" is checked for manner of death (Item 37). This includes all motor vehicle deaths. The item must be completed for decedents ages 14 years or over and may be completed for those less than 14 years of age, if warranted.

Enter "Yes" if the injury occurred at work. Otherwise enter "No." An injury may occur at work regardless of whether the injury occurred in the course of the decedent's "usual" occupation.

Examples of injury at work and injury not at work follow:

Injury at work

Injury while working or in vocational training on

job premises

lot on job premises

Injury while working for pay or compensation.

including at home

Injury while working as a volunteer law enforcement

official etc.

Injury while traveling on business, including to or from

business contacts

These guidelines were developed jointly by: The National Association for Public Health Statistics and

Information Systems (NAPHSIS), the National Institute of Occupational Safety and Health (NIOSH),

the National Center for Health Statistics (NCHS), and the National Center for Environmental Health and Injury Control (NCEHIC). For questions contact the State vital statistics office.

\section{LOCATION OF INJURY (Street and Number, City or Town, State, Apartment No., ZIP Code)}

Enter the complete address where the injury took place, including ZIP code. Fill in as many of the items as is known.

\section{DESCRIBE HOW INJURY OCCURRED}

Enter, in narrative form, a brief but specific and clear description of how the injury occurred. Explain the circumstances or cause of the injury, 
such as "fell off ladder while painting house," "driver of car ran off roadway," or "passenger in car in car-truck collision." Specify type of gun (e.g., handgun, hunting rifle) or type of vehicle (e.g., car, bulldozer, train, etc.) when relevant to circumstances. Indicate if more than one vehicle was involved; specify type of vehicle decedent was in. For motor vehicle accidents, indicate whether the decedent was a driver, passenger, or pedestrian.

If known, indicate what activity the decedent was engaged in when the injury occurred (e.g., playing a sport, working for income, hanging out at a bar).

In cases of accidental death, Items 38-43 are used in justifying the payment of double indemnity on life insurance policies. They are also needed for a more accurate determination of causes of death. Information from these items forms the basis of statistical studies of occupational injuries.

\section{IF TRANSPORTATION INJURY, SPECIFY:}

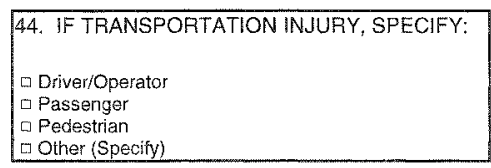

Specify role of decedent (e.g., driver, passenger) in the transportation accident. "Driver/Operator" and "Passenger" should be designated for modes other than motor vehicles such as bicycles. "Other" applies to watercraft, aircraft, animal, or people attached to outside of vehicles (e.g., "surfers") but are not bonafide passengers or drivers.

Details will help assign deaths to categories that may be used to assess trends and effectiveness of safety programs.

\section{5-49 CERTIFIER}

\section{CERTIFIER (Check only one)}

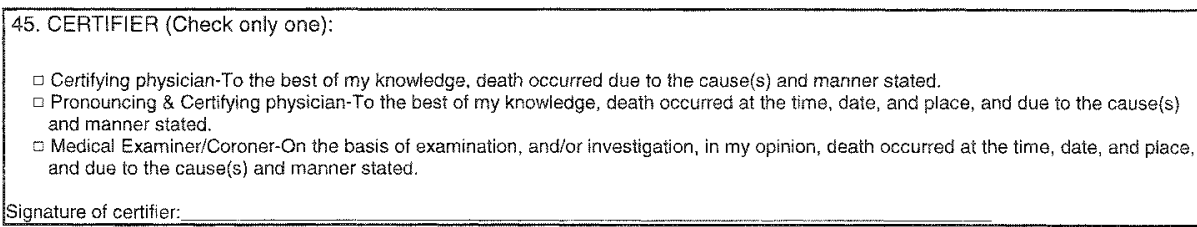

The Certifying physician is the person who determines the cause of death (Item 32). This box should be checked only in those cases when the person 
who is completing the medical certification of cause of death is not the person who pronounced death (Items 24 and 25). The certifying physician is responsible for completing Items 32-49.

The Pronouncing \& Certifying physician box should be checked when the same person is responsible for completing Items 24 through 49, that is, when the same physician has both pronounced death and certified to the cause of death. If this box is checked, Items 26-28 should be left blank.

The Medical Examiner/Coroner box should be checked when investigation is required by the Post Mortem Examination Act and the cause of death is completed by a medical examiner or coroner. The medical examiner or coroner is then responsible for completing Items 24-46.

If the attending physician is available to certify the fact of death, Items 26-28 should not be completed; the attending physician should then complete Items 24, 25, 29-37, and 45-49 as both pronouncing and certifying physician.

The two-physician certifier concept allows a hospital physician to certify to only the fact and time of death so the body can be released to the funeral director. The attending physician should complete the cause-of-death section. This certification method should result in improved data on cause of death because the physician having the most knowledge about the case completes the cause-of-death section.

Signature of certifier

The physician who certifies to the cause of death in Item 32 signs the certificate in permanent black ink. Jurisdictions with an electronic death certificate may allow electronic authentication. The degree or title of the physician should also be indicated. Rubber stamps or facsimile signatures are not permitted.

\section{NAME, ADDRESS, AND ZIP CODE OF PERSON COMPLETING CAUSE OF DEATH (ITEM 32)}

Type or print the full name and address of the person whose signature or authentication appears in Item 45.

This information is used by the State office of vital statistics for querying the certifier when a question about cause of death arises.

\section{LICENSE NUMBER}

Enter the State license number of the physician who signs or authenticates the certificate in Item 45 . 
This number assists in State quality control programs when it is necessary to contact the certifier for additional information concerning the death.

\section{DATE CERTIFIED (Month, Day, and Year)}

Enter the exact month, day, and year that the certifier signed the certificate.

Enter the full name of the month-January, February, March, etc. Do not use a number or an abbreviation to designate the month.

These items are of legal value in attesting that the medical certification was completed and signed within the time limit required by statute. 


\section{References}

1. Pates RD, Scully KW, Einbinder JS, et al. Adding value to clinical data by linkage to a public death registry. Medinfo 2001. London. 2001.

2. National Center for Health Statistics. Report of the panel to evaluate the U.S. standard certificates. Hyattsville, Maryland. 2000. (Addenda, 2001).

3. Hetzel AM. History and organization of the vital statistics system. National Center for Health Statistics. Hyattsville, Maryland. 1997.

4. National Center for Health Statistics. Model State vital statistics act and regulations: 1992 revision. Hyattsville, Maryland: Public Health Service. 1995.

5. World Health Organization. International statistical classification of diseases and related health problems, tenth revision. Geneva: World Health Organization. 1992.

6. Hanzlick R, Hunsaker III JH, Davis G J. A guide for manner of death classification. NAME. 2002. Accessed at http://www.thename.org/Library/Manner of_deathv1.pdf on 4/16/2002.

7. National Center for Health Statistics. Instructions for completing the causeof-death section of the death certificate. Hyattsville, Maryland: National Center for Health Statistics. Accessed at http://www.cdc.gov/nchs/about/major/ dvs/handbk.htm on 4/16/2002.

8. National Center for Health Statistics. Instructions for completing the causeof-death section of the death certificate for injury and poisoning. Hyattsville, Maryland: National Center for Health Statistics. Accessed at http://www.cdc. gov/nchs/about/major/dvs/handbk.htm on 4/16/2002.

9. National Center for Health Statistics. Possible solutions to common problems in death certification. Hyattsville, Maryland: National Center for Health Statistics. Accessed at http://www.cdc.gov/nchs/about/major/dvs/handbk.htm on 4/16/2002.

10. Hanzlick R. Writing cause-of-death statements. St. Louis, MO: National Association of Medical Examiners. Accessed at http://www.thename.org/ CauseDeath/COD_main_page.htm on 5/7/2002.

11. Hanzlick R (Ed). The medical cause-of-death manual. Northfield, Illinois: College of American Pathologists.

12. Hanzlick R (Ed). Cause-of-death statements and certification of natural and unnatural deaths. Northfield, Illinois: College of American Pathologists. 1997.

13. Texas Department of Health. Online CME medical certification of cause and manual of death. Accessed at http://www.tdh.state.tx.us/phpep/cme/cme_dc/ default.html on 4/20/2002. 
14. National Center for Health Statistics. Cause-of-death module. Hyattsville, Maryland: National Center for Health Statistics. Accessed at http://www.cdc.gov/ nchs/data/dvs/edc6.pdf on 4/20/2002.

15. National Center for Health Statistics. Mortality Web page. Hyattsville, Maryland: National Center for Health Statistics. Accessed at http://www.cdc.gov/ nchs/about/major/dvs/mortdata.htm on 4/20/2002. 


\section{Appendixes}

A. The U.S. Standard Certificate of Death $\ldots \ldots \ldots \ldots \ldots \ldots \ldots$

B. The Vital Statistics Registration System in the United States ... 54 


\section{Appendix A}

\section{U.S. Standard Certificate of Death}

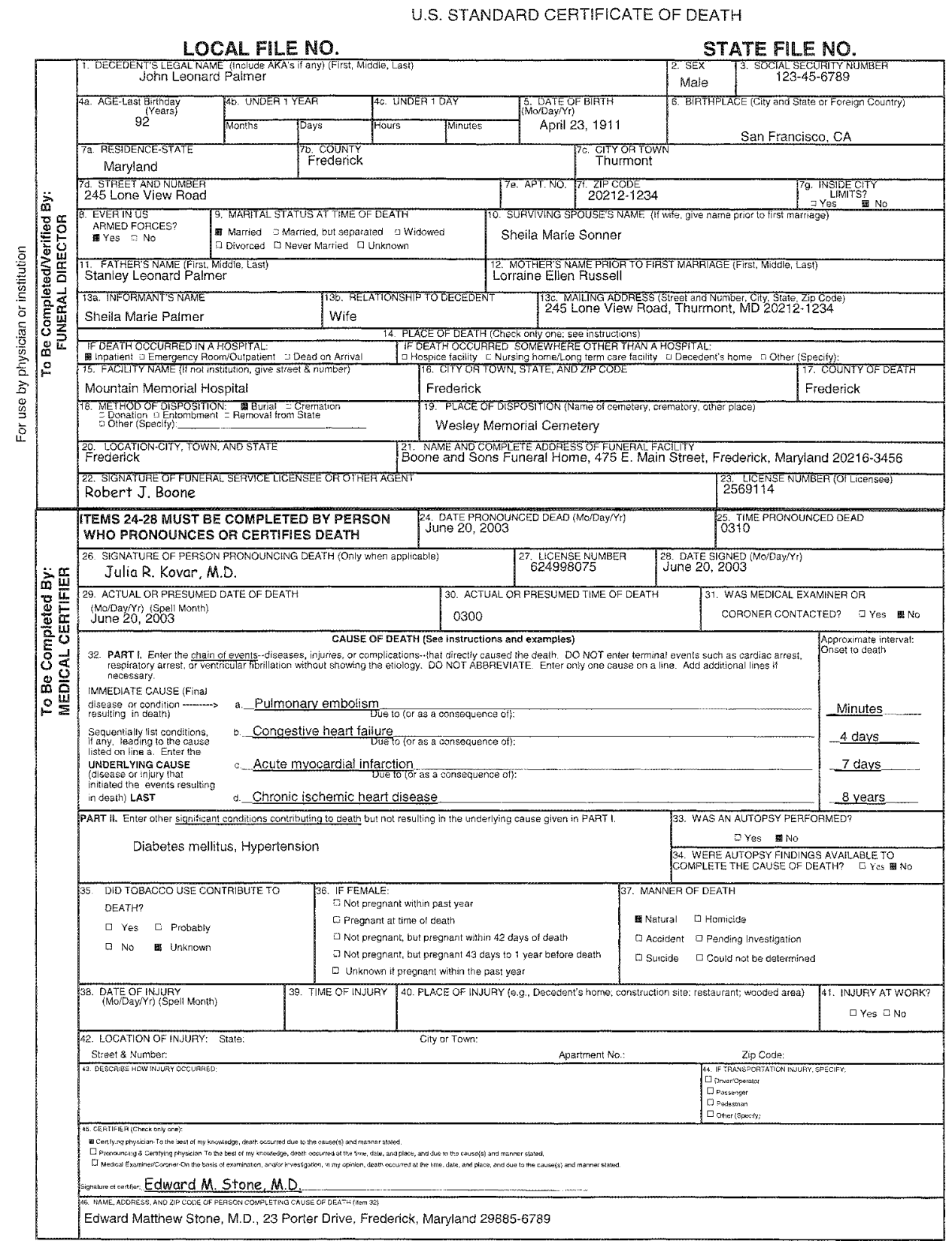




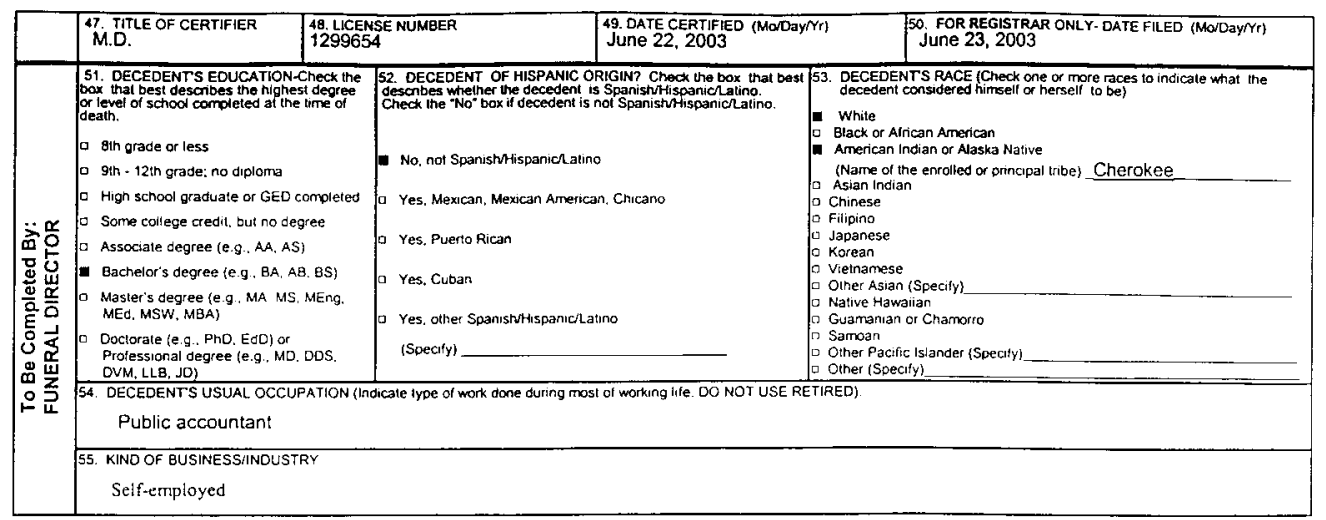




\section{Appendix B}

\section{The Vital Statistics Registration System in the United States}

The registration of births, deaths, fetal deaths, and other vital events ${ }^{1}$ in the United States is a State and local function. The civil laws of every State provide for a continuous, permanent, and compulsory vital registration system. Each system depends to a very great extent upon the conscientious efforts of the physicians, hospital personnel, funeral directors, coroners, and medical examiners in preparing or certifying information needed to complete the original records. For a graphic presentation of the registration system, see the accompanying chart, "The Vital Statistics Registration System in the United States."

Most States are divided geographically into local registration districts or units to facilitate the collection of vital records. A district may be a township, village, town, city, county, or other geographic area or a combination of two or more of these areas. In some States, however, the law provides that records of birth, death, and/or fetal death be sent directly from the reporting source (hospital, physician, or funeral director) to the State vital statistics office. In this system, functions normally performed by a local registration official are assumed by the staff of the State office.

In States with a local registrar system, the local registrar collects the records of events occurring in his or her area and transmits them to the State vital statistics office. The local registrar is required to see that a complete certificate is filed for each event occurring in that district. In many States, this official also has the duty of issuing burial-transit permits to authorize the disposition of dead human bodies. In many States, this official is also required to keep a file of all events occurring within his or her district and, if authorized by State law and subject to the restrictions on issuance of copies as specified by the law, may be permitted to issue copies of these records.

${ }^{1}$ Vital events are defined as live births, deaths, fetal deaths, marriages, divorces, and induced terminations of pregnancy, together with any change in civil status that may occur during an individual's lifetime. 
The State vital statistics office inspects each record for promptness of filing, completeness, and accuracy of information; queries for missing or inconsistent information; numbers the records; prepares indexes; processes the records; and stores the documents for permanent reference and safekeeping. Statistical information from the records is tabulated for use by State and local health departments, other governmental agencies, and various private and voluntary organizations. The data are used to evaluate health problems and to plan programs and services for the public. An important function of the State office is to issue certified copies of the certificates to individuals in need of such records and to verify the facts of birth and death for agencies requiring legal evidence of such facts.

The Centers for Disease Control and Prevention's National Center for Health Statistics (NCHS) is vested with the authority for administering the vital statistics functions at the national level (3). Electronic data files derived from individual records registered in the State offices or, in a few cases, copies of the individual records themselves, are transmitted to NCHS. From these data, monthly, annual, and special statistical reports are prepared for the United States as a whole and for the component parts-cities, counties, States, and regions-by various characteristics such as sex, race, and cause of death. These statistics are essential in the fields of social welfare, public health, and demography. They are also used for various administrative purposes, in both business and government. NCHS serves as a focal point, exercising leadership in establishing uniform practices through model laws, standard certificate forms, handbooks, and other instructional materials for the continued improvement of the vital statistics system in the United States. 
The Vital Statistics Registration System in the United States

\begin{tabular}{|c|c|c|c|}
\hline $\begin{array}{l}\text { Responsible } \\
\text { Person or } \\
\text { Agency }\end{array}$ & $\begin{array}{c}\text { Birth } \\
\text { Certificate }\end{array}$ & $\begin{array}{c}\text { Death } \\
\text { Certificate }\end{array}$ & $\begin{array}{c}\text { Fetal } \\
\text { Death Report }\end{array}$ \\
\hline Hospital authority & $\begin{array}{l}\text { 1. Completes entire certificate using } \\
\text { mother and facility worksheets. } \\
\text { 2. Files certificate with local office } \\
\text { or State office per State law. }\end{array}$ & $\begin{array}{l}\text { When death occurs in hospital, may } \\
\text { initiate preparation of certificate: } \\
\text { Completes information on name, date, } \\
\text { and place of death; obtains certification of } \\
\text { cause of death from physician; and gives } \\
\text { certificate to funeral director. } \\
\text { NOTE: If the attending physician is } \\
\text { unavailable to certify to the cause of } \\
\text { death, some States allow a hospital } \\
\text { physician to certify to only the fact and } \\
\text { time of death. With legal pronouncement } \\
\text { of the death and permission of the } \\
\text { attending physician, the body can then } \\
\text { be released to the funeral director. The } \\
\text { attending physician still must complete } \\
\text { the cause-of-death section prior to final } \\
\text { disposition of the body. }\end{array}$ & $\begin{array}{l}\text { 1. Completes entire report using patient } \\
\text { and facility worksheets. } \\
\text { 2. Obtains cause of fetal death from } \\
\text { physician. } \\
\text { 3. Obtains authorization for final } \\
\text { disposition of fetus. } \\
\text { 4. Files report with local office or State } \\
\text { office per State law. }\end{array}$ \\
\hline Funeral director & & $\begin{array}{l}\text { 1. Obtains personal facts about decedent } \\
\text { and completes certificate. } \\
\text { 2. Obtains certification of cause of death } \\
\text { from attending physician or medical } \\
\text { examiner or coroner. } \\
\text { 3. Obtains authorization for final disposition } \\
\text { per State law. } \\
\text { 4. Files certificate with local office or State } \\
\text { office per State law. }\end{array}$ & $\begin{array}{l}\text { If fetus is to be buried, the funeral director } \\
\text { is responsible for obtaining authorization } \\
\text { for final disposition. } \\
\text { NOTE: In some States, the funeral } \\
\text { director, or person acting as such, is } \\
\text { responsible for all duties shown above } \\
\text { under hospital authority. }\end{array}$ \\
\hline $\begin{array}{l}\text { Physician or other } \\
\text { professional attendant }\end{array}$ & $\begin{array}{l}\text { For in-hospital birth, verifies accuracy } \\
\text { of medical information and signs } \\
\text { certificate. For out-of-hospital birth, } \\
\text { duties are same as those for hospital } \\
\text { authority, shown above. }\end{array}$ & $\begin{array}{l}\text { Completes certification of cause of death } \\
\text { and signs certificate. }\end{array}$ & $\begin{array}{l}\text { Provides cause of fetal death and } \\
\text { information not available from the medical } \\
\text { records. }\end{array}$ \\
\hline
\end{tabular}




\begin{tabular}{|c|c|c|c|}
\hline $\begin{array}{l}\text { Local office }{ }^{\star \star} \text { (may be local } \\
\text { registrar or city or county } \\
\text { health department) }\end{array}$ & $\begin{array}{l}\text { 1. Verifies completeness and } \\
\text { accuracy of certificate and queries } \\
\text { incomplete or inconsistent certificates. } \\
\text { 2. If authorized by State law, makes } \\
\text { copy or index for local use. } \\
\text { 3. Sends certificates to State registrar. }\end{array}$ & $\begin{array}{l}\text { 1. Verifies completeness and accuracy of } \\
\text { certificate and queries incomplete or } \\
\text { inconsistent certificates. } \\
\text { 2. If authorized by State law, makes copy } \\
\text { or index for local use. } \\
\text { 3. If authorized by State law, issues } \\
\text { authorization for final disposition on receipt } \\
\text { of completed certificate. } \\
\text { 4. Sends certificates to State registrar. }\end{array}$ & $\begin{array}{l}\text { If State law requires routing of fetal death } \\
\text { reports through local office, the local office } \\
\text { performs the same functions as shown for } \\
\text { the birth and death certificate. }\end{array}$ \\
\hline $\begin{array}{l}\text { City and county health } \\
\text { departments }\end{array}$ & \multicolumn{3}{|c|}{$\begin{array}{l}\text { 1. Use data derived from these records in allocating medical and nursing services. } \\
\text { 2. Follow up on infectious diseases. } \\
\text { 3. Plan programs. } \\
\text { 4. Measure effectiveness of services. } \\
\text { 5. Conduct research studies. }\end{array}$} \\
\hline $\begin{array}{l}\text { State registrar, office of vital } \\
\text { statistics }\end{array}$ & \multicolumn{3}{|c|}{$\begin{array}{l}\text { 1. Queries incomplete or inconsistent information. } \\
\text { 2. Maintains files for permanent reference and is the source of certified copies. } \\
\text { 3. Develops vital statistics for use in planning, evaluating, and administering State and local health activities and for research } \\
\text { studies. } \\
\text { 4. Compiles health-related statistics for State and civil divisions of State for use of the health department and other agencies } \\
\text { and groups interested in the fields of medical science, public health, demography, and social welfare. } \\
\text { 5. Sends data for all events filed to the National Center for Health Statistics. }\end{array}$} \\
\hline $\begin{array}{l}\text { Centers for Disease Control } \\
\text { and Prevention, National } \\
\text { Center for Health Statistics }\end{array}$ & \multicolumn{3}{|c|}{$\begin{array}{l}\text { 1. Evaluates quality of State vital statistics data and works with States to assure quality. } \\
\text { 2. Compiles national statistical data file and runs edits to fully process data. } \\
\text { 3. Prepares and publishes national statistics of births, deaths, and fetal deaths; constructs the official U.S. life tables and related } \\
\text { actuarial tables. } \\
\text { 4. Conducts health and social research studies based on vital records and on sampling surveys linked to records. } \\
\text { 5. Conducts research and methodological studies in vital statistics methods, including the technical, administrative, and legal } \\
\text { aspects of vital records registration and administration. } \\
\text { 6. Maintains a continuing technical assistance program to improve the quality and usefulness of vital statistics. } \\
\text { 7. Provides leadership and coordination in the development of standard certificates and report and model laws. }\end{array}$} \\
\hline
\end{tabular}

** Some States do not have local vital registration offices. In these States, the certificates or reports are transmitted directly to the State office of vital statistics. 
DHHS Publication No. (PHS) 2003-1108 03-0002 (4/2003) 